The pickling solutions used for curing meats contain uswally salt. saltpeter and sugar; and after wse they contain also the class of substances known as meat bases and varions proteins. Cured meats themselves also contain all these componnds. The Keldahl method and its morti. fications are inapplicable, therefore, to the determination of total ni trogen in curel meats and pickling solutions. Various methods were tried in this laboratory to atrire at the amonnt of total nitrogen in these two products and the following was devised for the purpose: (I) determine nitric nitrogen by the schloessing-llagner method; (2) in another portion eletermine nitrogen exchding nitrates by adding to the substance in the Kjeldahl flask $10 \mathrm{ce}$. more or less of saturated ferrous chloride solution and boiling with dilute sulphutic aciu until nitrates are destroved. Then proced with the detemination of the remaining

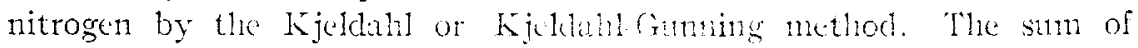
(I) and (2) gives the total nitroget. I lest solution was mate containing ten granls ammonitm chloride, ten Grims potissinn nitrate and zon

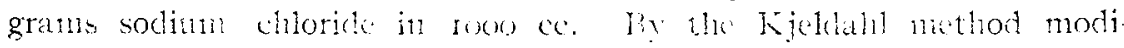
fird to include nitrates the following giantities of total nitrogen were found in three deteminations in aliquen parts of this solution: 0.09 (n)

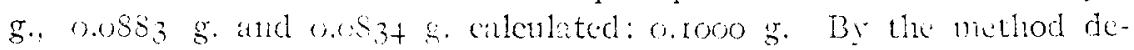
scriber above the following quantitics we found: nitric nitrogen $0.03+7$

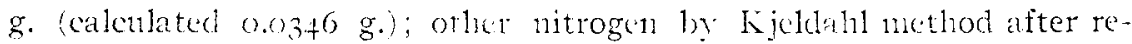
moval of nitrates, $0.0653 \mathrm{~g}$. (caleulated $0.0654 \mathrm{~g}$. ); total nitrogen fomm

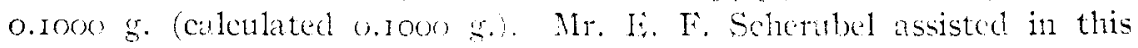
work.

W. I). RICIARDSON.

IABORA TOKS OH SWIHT L CO.

Cincis:is

\title{
REVIEWS.
}

\section{REVIEW OF ANALYTICAL WORK DONE IN I906.}

\author{
HY BENION IALES \\ keceivert December 15, byo-.
}

In this review the only change from the plan of previous ones is that American work has been included. 'The writer's acknowledgment of his indebtedness to the Chemisches Zentralblatt for general grouping of subjects and for abstracts is due again and is here made. He has mado use occasionally also of abstracts in the Journals of the London Chemical Society and Society of Chemical Industry.

\section{General Analysis.}

Apparatus.-A new Orsat apparatus was proposed by Bendemann ( $J$. Gasbel., 49, 583 , from $Z$. Vor. Ing.) for analysis of the new power gases which contain something like $30 \%$ of carbon monoxide, $12 \%$ of hydrogen and only traces of methane. "Wo cuprous chloride pipettes are used, and where considerable amounts of oxygen are to be absorbed either 
phosphorus or a second pyrogallol pipette. About $30 \mathrm{cc}$. of gas are taken for the combustion. The combustion pipette is best covered with a water jacket connected with the water mantle of the burette. Lux (Ibid., 49, 475) described the Raupp gas calorimeter as better than the Junker. It consists chiefly of a copper cylinder whose lower part is solid, the hollow upper part carrying a thermometer divided into tenths. Under the copper body is placed at a certain time the gas flame, whose height has been previously determined, and the time necessary for the thermometer to rise $10^{\circ}$ is noted. The apparatus is standardized by means of gases of known heating value, so from a table and from the measured time the heating value can be calculated. McDowall (Chem. News, 94, I04) recommended the use, instead of the ivory scale on balances, of a brass one which should move by a horizontal screw under the box engaging a tooth attached to the scale. After the pans are released the scale may be moved till the pointer swings equally on either side of the zero. An apparatus was described by Weimern (J. russ. phys.chem. Ges. 38, 228) for determining the solubility of solids in liquids. It consists essentially of two glass cylinders held together by an oblique tubular connection projecting downward inside the lower cylinder. The liquid is saturated with the solid in the upper cylinder which has a large stirrer that is used also to force the liquid through the side arm containing a wadding tampon and so into the weighed glass receiving vessel. The lower cylinder has an arrangement by which the cover of the weighing vessel may be placed before the vessel is removed from the cylinder. It is then weighed, the liquid evaporated, and weighed again.

Combustion and Heating Value.-A good deal of work was published on the various combustion methods noted in previous reviews. Carrasco and Plancher (Gazz. chim. ital., 36 II, 492) gave more details concerning their method of internal electrical heating in the use of which priority was claimed by Morse and Gray $(A m$. Chem. J., 35, 45I $)$. Dennstedt $(Z$. angew. Chem., 19, 517; $Z$. anal. Chem., 45, 26) and Dennstedt and Hassler (J. Gasbel, 49, 45) gave more details with regard to Dennstedt's simplified combustion method. The second of these three articles is in reply to the criticisms of Hermann which were maintained by the latter $(Z$. anal. Chem., 45, 236). The last of the three contains the modifications of the method necessary for the analysis of coals. Holde (Ber., 39, 1615) and Holde and Schlüter (Mitth. kgl. Materialprüfungsamt Gross Lichterfelde West, 24, 268) gave the results of some experiments with the Dennstedt and Heraeus furnaces, mentioning as some of the difficulties of Dennstedt's rapid method those of obtaining the correct agreement between oxygen addition and rapidity of combustion, the occasional failure of the platinum quartz to glow as a criterion for the proper carrying out of the method and the necessity of constant watching. Dennstedt (Ber., 39, 1623) replied, saying that the commonest error in the rapid method is the too rapid volatilization of the substance. This should be run with an oxygen current of about $60 \mathrm{cc}$. per minute instead of running the oxygen current according to the rapidity of volatilization. Von Konek (Ibid., 39, 2263) added his favorable experiences with the Heraetis furnace. Marek (J. pr. Chem. [2] 73, 359; 74, 237) recommended the use of a $5 \mathrm{~cm}$. layer of copper oxide or copper oxide asbestos in combustion analyses instead of the layer of ordinary length. This proposal was criticized by Dennstedt (Ibid., [2] 73, 570). 
A number of methods for determining the halogens in organic compounds were proposed. 'That of Berry (Chom. News, 94, 188) is a combination of those of Piria and Schiff (ignition with sodium carbonate and lime) and the thiocyanate method of Volhard. The cooled mass is dissolved in dilute nitric acid ( $\mathrm{r}: 4)$, kept cool, excess of tenth-normal silver nitrate added, the silver halicle filtered and the filtrate titrated with tenthnormal potassium thiocyanate, using ammonimm iron alum as indicator. With substances containing iodine, sodium carbonate alone is used for the ignition. Moir (Proc. Chm. Soc., 22, 26r) heated the substance in a nickel cricible with io drops of water and pure caustic potast1 on a water bath, stirring with a platinum wire, then gradually decomposed the product with 0.5 to i gram of fincly pulverized potassium permanganate, evaporated and drove out the precipitated carbon by ignition. The cooled crucible was brought into a warm dilute solution of primary potassium sulphite, the solution acidified with acetic acid then filtered into a silver nitrate solution. The silver halide was determined as usual. Or the cooled crucible might be put into water, the solution acidified with acetic acicl till the manganate is converted into permanganic acid, the latter destrored with barinm peroxide, the filtered solution neutralized with prinary sodium carbonate and then titrated. Robinson (Am. Lhem. J., 35, 531) recommended a filling of the combustion tube as ustual with copper oxicle, placing also in it a cartridge filled with laad chromate, like Morse and 'laylor's (Ibid., 33, 602) arrangennent for the combution of stilphur-bearing compounds. Vaubel and Scheuer (Chem.Zto. 3I, 67) proposed to weigl out 0.2 to 0.5 gram of substance in a dry 150 to 200 ce. distilling flask, setting a separatory funnel in place in the neck of the flask. The side arm was connected with a Volhard flask in such a way that it did not dip into the silver nitrate. 30 to so ce. of concentrated sulphuric acid were added, the stopper of the separatory funnel closed, the liquid warmed gradually and a weak current of air passed through the apparatus either from the beginning or at the end of the experinent, according to the ease with which the gases are evolvecl. Iodine was driven ont of the side tube by warming. To insure the formation of silver iodide and not iodate halogent-free filter paper or metallic copper was placed in the clistilling flask to increase the amount of sulphur dioxide formed. In the Volhard flask silver halide and sliphite were formed, gathered into a beaker, treated with water annl about $50 \mathrm{cc}$ of concentrated nitric acid, boiled till sulphur dioxide was driven out or all silver sulplite was changed to sulphate, diluted till the sulplute clissolved and the halide determined by weighing or by titration of tlee silver in solution. Nitrogen may be determined at the same tinte. Bianchi (Boll. chim. fam., 45, 821) criticized this methor, saying that it was not in general usable for organic chlorine clerivatives he did not pass on its value for bromine and iodine derivatives. If it does work for these it may be simplified by using the Volhard volumetric method. "l"k Kjeldahl nitrogen determination may be made at the same time all right.

Gar..-Franzen $(B \in r ., 39$, 2otog) proposect the usc of sodiun hydrostlphite for the absorption of oxyget, $\mathrm{r}$ gram absorbing $64 \mathrm{cc}$. of the gas. $\mathrm{Na}_{2} \mathrm{~S}_{2} \mathrm{O}-\mathrm{H}_{2} \mathrm{O}+\mathrm{O}-2 \mathrm{NaHSO}_{2}$. 50 grams of the hydrostalphite are dissolved in $2,50 \mathrm{cc}$. of water and to $\mathrm{cc}$. of sodium hydroxide 
solution (500 grams in 700 grams of water) and the solution used in a Hempel pipette for solid substances filled with iron wire gauze. I cc. of this solution absorbs $10.7 \mathrm{cc}$. of oxygen. It has the advantages of being cheaper than pyrogallol; it may be used in weakly alkaline solution and has the same absorption at various temperatures; it may be used with gases containing carbon monoxide (ammoniacal cuprous chloride cannot) and it may be used at lower temperatures and in the presence of substances that hinder the oxidation of phosphorus. For Bunte burette determinations a weaker solution is used which has to be shaken for three minutes. Haber $(Z$. angew. Chem., I9, I418 and $Z$. Elektrochem., I2, 519) with Löwe had made by Zeiss a gas refractometer consisting of a prism telescope, a glass prism for the air or gas and a mirror. The observer looks at a luminous spot within the telescope. On looking into the instrument a dark shadow is seen which falls upon the scale in a position corresponding to the gas in the prism. The method has the advantage that the refractive index of the gas sample as compared with air remains the same as long as both are subjected to the same pressure and temperattre changes. If chimney gases be led through the prism an increase of $0.9 \%$ carbon dioxide causes the image to be displaced I division of the scale. The instrument can be adapted for photographic registration or the shadow can be made visible at a distance. The apparatus is sensitive to $0,000,0003$ in the refractive index, corresponding to a change of $0.2-0.25 \%$ carbon dioxide in chimney gases. Methane, hydrogen, hydrochloric and hydrocyanic acids can be determined in air with the same delicacy. "The delicacy is twice as great for acetylene and hydrogen sulphide, $2 \frac{1}{2}$ times as great for sulphur dioxide and nearly ro times as great for pentane and benzene vapor. Nowicki (Oesterr. Z. Berg.-Hüttenw., 54, 6) recommended oxidation with iodine pentoxide as the most satisfactory way to determine carbon monoxide, subsequently determining the carbon dioxide in various ways. $\mathrm{Hy}$ drogen sulphide is also easily oxidized. Acetylene acts on iodine pentoxide above $85^{\circ}$, but the carbon monoxide oxidation begins at $45^{\circ}$ and is finished at $88^{\circ}$. The pentoxide heated by itself begins to decompose at $165^{\circ}$ and the reaction is completed at $300^{\circ}$. Gautier and Clausmann (Compt. rend., I42, 485 ; Bull. soc. chim. [3] 35, 5I3) made a similar recommendation with regard to carbon monoxide.

Soil.-Hall, Miller and Marmu (Proc. Chem.Soc., 22, 103; J. Chem. Soc., 89, 595) found that the commonly used moist oxidation with chromium trioxide yields always 10 to $20 \%$ too low values because the oxidation of the carbon does not proceed completely to the dioxide. They inserted a short layer of copper oxide. Murray (Chem. News, 93, 40) used the following apparatus for the mechanical analysis of soils. An Erlenmeyer flask of about $200 \mathrm{cc}$. capacity without a flanged neck (neck of 2 to $3 \mathrm{~cm}$. diameter) is bound to a piece of glass tubing of the same diameter as its neck by means of stout rubber tubing. 5 grams of fine, air-dried earth suspended in ammonia solution are put into the flask, it and the tube are filled carefully with water, the tube opening is closed and the apparatus turned upside down, the mouth being brought into a dish filled with water. Immediately under the tube opening is placed a small porcelain dish which is replaced by others at stated times. The portion deposited in each dish is evaporated and weighed. In order 
to get a common basis for the expression of results Murray recommends uniting the particles that fall through I $\mathrm{cm}$. in $\mathrm{I}$, then $5,10,20$, 100 and 400 seconds.

Water.-Bruhns ( $Z$. anal. Chem., 45, 473) stated that barium carbonate reacts alkaline and is attacked by dilute oxalic acid, hence the determination of carbon dioxide in water by precipitation with barium hydroxide and back titration with tenth-normal oxalic acid without filtering leads to errors. He used a tube carrying above a stopcock a cylindrical vessel of 100 to $300 \mathrm{cc}$. capacity and placed just above the stopcock glass wool or wadding and on top of that paper pulp, thus making a filter. The measured sample was put into this ressel and protected from air by a 3 to $5 \mathrm{~mm}$. layer of benzene. The barium or calcium hydroxide solution was run in from a burette whose tip reached below the benzene layer. The mixture was carefully stirred, let stand to clear and the liquid run through the filter. 'The filtrate was caught under a 3 to $5 \mathrm{~mm}$. layer of benzene and was titrated in small portions. 'Tenthnormal oxalic acid was used for titration and neutralized phenolphthalein for indicator if the water contained no magnesinm. If ammonium chloride had to be added to keep magnesium in solution litmus or methylorange was used. It is not advisable to titrate under the benzene layer because acid can be occluded by it. Buisson (Compt. rend. I43, 289 and $J$. pharm. chim. [6] 24, 289) studied the determination of ammo. nia by Nessler's reagent. His analyses of the precipitate fron ammonium chloride and the reagent lead to the formula $\mathrm{Hg} \mathrm{g}_{9} \mathrm{~N}_{4} \mathrm{I}_{6}$, agrecing with the work of François. The precipitate is soluble in potassium iodide, hence the reaction is reversible and some ammonia escapes detection (in one ease $2 \mathrm{I} \%$ ). The determination of ammonia carricd out by determining the mercury in the precipitate is therefore inexact. Drawe (Chem.-Ztg., 30, 530) determined nitric acid by evaporating Ioo ce. of water first with residue-free hydrochloric acid, then several times with water, then determining the chlorine in the solution of the residue. He subtracted from the total number of ce, of tenth-normal silver nitrate solution the number of $\mathrm{ce}$. used in titration of the same amount of water sample and the number of $\mathrm{cc}$. of tenth-normal acid combined in the dutermination of carbonate hardness in roo cc. The difference was calculated to nitric acicl. Kühn (Arbl. kais (resumiheitsamt., 23, 389) determined minimal amounts of lead by adding to 4 or 5 liters of the water a solution of $25 \mathrm{cc}$. of acetic acid and $500 \mathrm{cc}$. of sodium sulphide solution $(8: 500)$ mixed just before using. The coagulation of the colloidal lead sulphide was aided by the addition of too grams of sodinm nitrate and the liquid was shaken with 2 grams of short fibered asbestos. The precipitate was filtered on asbestos, using suction, the lead sulphide oxidized by hydrogen peroxide containing a little nitric acid and the lead sulphate dissolved in sodinm acetate solution. The rest of the method is that of Dichl and 'Topf (Dingler's pol. J., 246, 196; Z. anal. Chem., 26, 137, 277). It is accurate to I mg. of lead in I liter of water. Pholps ('Tins Jotr. $\mathrm{NAh}_{2}, 28,368$ ) determined small a mounts of copper by evaporating i liter of the water to about $75 \mathrm{cc}$. (for 0.1 to I gram of copper), and adding 2 to $5 \mathrm{ec}$ of stlphuric acid and electrolyzing, using the disin ats anode, with a current of $\mathrm{ND}_{100}=0.3$ ampere for 4 hours or over night with gentle stirring. The cathode was removed without interrupting the current 
and dipped into boiled nitric acid. This solution was evaporated to dryness, the residue taken up in water, put into a $100 \mathrm{cc}$. Nessler tube, filled to the mark and ro cc. of potassium sulphide solution (equal volumes of $10 \%$ caustic potash and saturated hydrogen sulphide solutions) added. The copper sulphide color appeared and was compared with the color in a similar tube of ro cc. of the potassium sulphide solution diluted with water and standard copper sulphate solution added (0.2 cc. at a time) till colors were the same. For I liter of water taken, I cc. of the copper sulphate solution is equivalent to a copper content of 0.2 : 1000000. Raschig ( $Z$. angew. Chem., I9, 334) determined sulphuric acid by adding to the sample one-twentieth of its volume of a concentrated benzidine solution, stirring and allowing to stand is minutes. If there were no precipitate the water contained I.5 mg. of sulphur trioxide per liter or less. The precipitate was washed by suction, using very little water, and titrated with tenth-normal sodium hydroxide (I cc. = $4 \mathrm{mg}$. sulphur trioxide). There should be added for the benzidine loss $1.5 \mathrm{mg}$. Iron does not interfere if $\mathrm{I}$ to $2 \mathrm{cc}$. of a $\mathrm{I} \%$ hydroxylamine hydrochloride solution be added before the benzidine precipitation. Scriba ( $Z$. physik. chem. Unterricht, 19, 298) stated that a paper strip dipped in a solution of $\mathrm{r}$ gram of ferrous ammonium sulphate in $20 \mathrm{cc}$. of water, dried and rubbed with pulverized potassium ferricyanide will give a deep blue spot with the smallest amount of water.

Volumetric.-Acree and Brunel ( $\mathrm{Am}$. Chem. J.,36, I I 7) prepared a standard solution of hydrochloric acid by filling a clean liter flask nearly full of water, running through a single holed rubber stopper a glass tube with a long capillary reaching nearly to the bottom of the flask, weighing this to o.ooI gram with another flask as tare, then passing into it a current of dry hydrochloric acid gas till the increase in weight is a little more than I gram molecule. The flask is cooled to room temperature before the last weighing. The solution is then made up to the mark and the extra water added from a burette. A further standardization is unnecessary. Solutions of other gases obtainable dry, as hydrobromic and hydriodic acids, hydrogen sulphide, sulphur dioxide in any solvent, may be thus prepared. They gave also an improvement over the ordinary gravimetric method for standardizing hydrochloric or sulphuric acid solutions. About 4.i2 grams of twice recrystallized primary sodium carbonate are neutralized with the necessary amount of acid (using methyl orange). The end point is reached when a weak rose-red color persists after some standing in a vacuum. The solution is evaporated to dryness in a weighed platinum dish and the residue heated to constant weight. From the weight of the sodium chloride or sulphate and the volume or weight of solution used it is easy to calculate the strength of acid. The method can be used with all acids, giving sodium salts that can be dried and weighed. Richardson ( $J$. Chem. Ind., 26, 78) standardized sulphuric acid by neutralizing $5 \mathrm{cc}$. of dilute weighed acid with filtered saturated barium hydroxide solution, using phenolphthalein. The neutral solution was evaporated on the water bath and the barium sulphate ignited and weighed. Riegler (Bull. assoc. chim. sucr. dist., 24, 528) recommended ammonium triiodate $\left[\mathrm{NH}_{4} \mathrm{H}_{2}\left(\mathrm{IO}_{3}\right)_{3}\right]$ as an original standardizing material. For tenth-normal solution 3.025 grams of the salt are dissolved in roo $\mathrm{cc}$. of boiling 
water and this diluted to I liter. To standardize sodium thiosulphate $40 \mathrm{cc}$. of water are put into a llask with I gram of potassium iodide, I cc. of hydrochloric acid (d. I.2) and $10 \mathrm{cc}$. of the above triiodate solution and the mixture titrated as usual with thiosulphate. $3 \mathrm{NH}_{4} \mathrm{H}_{2}\left(\mathrm{IO}_{3}\right)_{3}+$ $6 \mathrm{Na}_{2} \mathrm{~S}_{2} \mathrm{O}_{3}=3 \mathrm{Na}_{2} \mathrm{~S}_{4} \mathrm{O}_{6}+{ }_{5} \mathrm{NaIO}_{3}+\mathrm{NaI}+3 \mathrm{IH}_{2}\left(\mathrm{O}=3 \mathrm{NH}_{1} \mathrm{IO}_{3}\right.$. The triiodate acts as a dibasic acid and so can be used directly for alkalimetry with luteol, Congo red or diazonitranilineguaiacol as indicator. The triiodate neutralized by sodium hydroxide is no longer affected by sodium thiosulphate so the base to be determined can be treated with an excess of triiodate and the excess titrated back with thiosulphate. Standardization of tenth-normal acid may also be effected gas rolumetrically by letting the triiodate act on hydrazine sulphate and determining the nitrogen $(Z$. anal. Chem., 42, 677). Wagner, Rink and Schultze (Chem.-Ztg., 30, I181) suggested the second method of Acree and Brunel for the standardization of acids and bases. They stated also that where there are tables showing the relation between refraction and concentration the Zeiss immersion refractometer may be used to determine quantitatively the reaction product. They gave a table for the relation between refraction and concentration of nitric acid.

Ahlum (Proc. Chem. Soc., 22, 63; J. Chem. Soc. 89, 470) gave a volumetric determination of free acid in the presence of iron salts, the iron being precipitated with monosodium phosphate, the phosphate filtered out and the filtrate titrated with sodiun hydroxide. The acid formed as a result of the iron precipitation, for example, $\mathrm{Fe}_{2} \mathrm{Cl}_{6}+2 \mathrm{NaH}_{2} \mathrm{PO}_{4}=$ : $2 \mathrm{FePO}_{+}+2 \mathrm{NaCl}+{ }_{4} \mathrm{HCl}$, is corrected for. Rupp $(Z$. anul. Chem., $45,687)$ stated that permanganate oxidations run more rapidly and vigorously in alkaline than in acid solution, hence it is advisable in some cases to oxidize in alkaline solution, then to acidify and titrate back the excess of permanganate according to Raschig (Ber., 38, 39II). Iormic and nitrous acids are cases given as examples. The formate solution is warmed in a glass stoppered flask with considerable excess of permanganate standardized against sodium thiosulphate and with 0.5 gram of pure dry sodium carbonate for 15 to 30 ninutes on the water bath, diluted after cooling with about $75 \mathrm{cc}$. of water, $25 \mathrm{cc}$. of clilute sulphuric acid are adcled and $I$ to 2 grams of potassium iodide, then the liberated iodine is titrated with tenth-normal thiosulphate ( $\mathrm{ccc}=20.0023$ gram of formic acid $=0.0023$ gram of nitrous acid anion).

Brandt ( $Z$. anal. (hem. 45, 95) found that the violet color of diphenylcarbohydrazide (observed by Cazeneuve [Chem.-Ztg., 24, 684; Bull. soc. chim. [3] 25, 758]) could be used to detect the end point of the bichromate iron titration if a sufficient amount of hydrochloric acid were present with the manganese sulphate solution containing phosphoric acid of the Reinhard method. There should be at least 60 to $80 \mathrm{cc}$. of hydrochloric acid [d. I. I2] added to I. 5 liters of water containing roo cc. of the manganese solution $(6 \mathrm{~kg}$. of sulphate, 33 liters of dilute sulphuric acid $[1: 3]$ and 3 liters of phosphoric acid [ $(1 . \mathrm{I} .7]$ diluted to 60 liters), the iron solution and the indicator (about $5 \mathrm{cc}$. of $0.1 \%$ solution). Then on titrating a red-violet color is obtaincd, beconing a mixed color as the green chromium salt increases till finally a sharp change to purc green is obtained at the end. Without the acid the decomposition of the coloring matter is too cuergetic and takes place before the iron is oxidized. Iron in announts less than 
0.2 gram are to be titrated without the manganese sulphate solution which tends to weaken the oxidizing action on the coloring matter. With less than o.I gram ferric chloride must be added. Corsini (Giorn. chim. farm., 55, 200) recommended the use of tropaeolin $O O$ in alcoholic solution as indicator in the determination of free mineral acids in bromatology instead of methyl violet. The color change from yellow to red-violet is sharper and more delicate than that of the latter, for example, for sulphuric acid I: 20000 ( $\mathrm{I}$ : roo00 with methyl violet) and for hydrochloric acid I.5 to $2: 2000$ ( 2 to 2.5 : I000). Fenton (Proc. Camb. Phil. Soc., I3, 298) stated that the previously described condensation derivative of methylfurfuraldehyde of the composition $\mathrm{C}_{11} \mathrm{H}_{8} \mathrm{O}_{4}$ may be used as an indicator for strong acids and bases. A paper prepared from aqueous alcoholic solution gives with primary amines in acetic acid solution an intense green color destroyed by mineral acids; with urea in the presence of strong hydrochloric acid a blue color; with alkalies a violet-blue color destroyed by acids and disappearing on strong dilution. If the substance be melted at $120^{\circ}$ with urea a colorless base is obtained giving a blue color with acids. Another acid indicator is obtained by boiling the compound with $\beta$-naphthylamine in alcohol solution which gives with weak acids an intense green color. Salm $(Z$. Elektrochem., I2, 99, and $Z$. physik. Chem., 57, 47I) stated that by dilution of hydrochloric acid it is possible to prepare a series of standard solutions of varying hydrogen ion concentration. Solutions near the neutral point are better prepared by mixing tenth-normal monosodium and disodium phosphate solutions. For each one of these concentrations an indicator can be found which will give a color change. By comparison with suitably chosen standards the hydrogen ion concentration of solutions may be accurately determined, for example, for oxalic acid $\mathrm{K}=0.09$ (O.I), tartaric $0.00 I I(0.00097)$, fumaric $0.001 \mathrm{I}$ (0.00093) and camphoric $0.000,025(0.000,0225)$. The figures in parentheses are from Ostwald's electrical conductivity measurements. The dissociation constant of an indicator base or acid is equal to the hydroxyl or hydrogen ion concentration of a solution half dissociated. With two-colored indicators like litmus such a solution is formed at the color change. With singly colored ones like phenolphthalein this solution is obtained by adding acid to the completely reddened liquid till the color intensity has half fallen away. The following dissociation constants are given:

$$
\text { Indicator acids. }
$$

Methyl orange..... K $=4.6 \times 10^{-4}$ p-Nitrophenol..........2.3 $\times 10^{-7}$ Rosolic acid........... I.I $\times 10^{-8}$

Alizarin ............. $8.8 \times 10^{-9}$

Phenolphthalein........ $8.0 \times \mathrm{ro}^{-10}$
Indicator bases.

Cyanine . ............ $=4.2 \times 10^{--8}$

Dimethylaminoazobenzene... .1.45 $\times 10^{-1}$

Indicators and color changes for definite hydrogen ion concentrations are:

\begin{tabular}{|c|c|}
\hline Concentration of $\mathrm{H}$ & Indicator. \\
\hline $2 \mathrm{~N}$ & Manvein \\
\hline $\mathbf{r N}$ & \\
\hline $\left.1 \times 10^{-1} \mathrm{~N}\right\}$ & $"$ \\
\hline $\left.\mathrm{I} \times 10^{-2} \mathrm{~N}\right\}$ & “" \\
\hline $1 \times 10^{-3} \mathrm{~N}$ & “ \\
\hline $\mathrm{I} \times 10^{-4} \mathrm{~N}$ & Congo red \\
\hline
\end{tabular}

Color change.

Yellow-green

Green-green blue

Green blue-blue

Blue-violet

Blue-violet 
Concentration of $\mathrm{H}^{+}$.

\begin{tabular}{|c|c|}
\hline $1 \times 10^{-5} \mathrm{~N}$ & Congo red \\
\hline$I \times 10^{-6} \mathrm{~N}$ & Sodium alizarinsulphonate \\
\hline $\mathrm{I} \times 10^{-i} \mathrm{~N}$ & Rosolic acid \\
\hline$I \times 10^{-8} \mathrm{~N}$ & “ \\
\hline $1 \times 10^{-8} \times$ & $\underset{\text { Phenolphthalein }}{\text { Pf }}$ \\
\hline $\mathrm{I} \times 10^{1}-{ }^{11} \mathrm{~N}$ & $\alpha$-naphtolbenzoin \\
\hline$\left.\times 10^{-12} \mathrm{~N}\right]$ & Tropaeolin \\
\hline$I \times 10-13 N$ & Trinitrobenzene \\
\hline$I \times 10^{-14} \mathrm{~N}$ & Benzopurpurin \\
\hline $1 \times 10^{-.15} \mathrm{~N}$ & Safranine \\
\hline
\end{tabular}

Indicator.

Congo red

Sodium alizarinsulphonate

Schoorl (Chem. Weekblad, 3, 719, 771, bo7) defined color indicators

Color change.

Violet-scarlet

Brown-red

Bright brownish red-rose

Rose-red

Colorless-rose

Rose-red

Green-green blue

Green yellow-orange

Colorless-orange

Yellow(red)-rose

Rose red-violet as those coloring matters which possess distinctly different colors according to whether the aqueous solution into which they are put contains free hydrogen or hydroxyl ions. In the first casc they show "acid" color, in the second, "basic" color. On transition from one color to the other they show "transition" color. An acid delicate indicator is one that shows transition color in aqueous solution that contains hydroxyl ions, as phenolphthalein, tropacolin $O() O$ and curcumin; alkali delicate indicators are the opposite like p-nitrophenol, lacmoid. Congo and methyl orange and neutral indicators are those whose transition color shows in aqueous solutions containing both ions, as rosolic acid and litmus. The different behavior of indicators in pure water is explained easily. on the basis of the difference in their sensibility guotients $\mathrm{H}: \mathrm{OH}$; the behavior of solutions set at transition color on warming is explained by the change in that same quotient as a result of the increased dissociation of water molecules. The following results are given in a couple of tables:

Concentration of

Indicator. $\mathrm{H}^{+} \mathrm{OH}^{-} \mathrm{II}: \mathrm{OH}^{-}$

Phenolphthalein 10-! $\mathrm{IO}^{-5} \mathrm{IO}^{-4}$

Tropaeolin 000 IO $^{-3} \quad 10^{-6} \mathrm{IO}^{-4}$

Curcumin. . . . . 10 $10^{-7.5}$ 10 $-8.5 \mathrm{IO}^{-1}$

Rosolic acid... . $\mathrm{IO}^{-7} \quad \mathrm{IO}^{-7} \quad$ I

Litmus. . . . . 1 $\mathrm{IO}^{-7} \mathrm{rO}^{-7}$ I

p.Nitrophenol . 10-6 $10^{-8} \mathrm{IO}^{2}$

Lacmoid ...... I0 IO $^{-6} \quad \mathrm{Ig}^{-8} \mathrm{IO}^{2}$

Congo........ $10^{-4} \quad 10^{-10} 10^{6}$

Methyl orange. . $10^{--4} \quad 10^{-10} \mathrm{IO}^{8}$
Color take: by culu 'ransition color in pure water tion with transition color. at roont temperature, color on warning.

$\begin{array}{lll}\text { Bright red } & \text { Colorless } & \text { Colorless } \\ \text { Orange } & \text { Yellow } & \text { Yellow } \\ \text { Brown-yellow } & \text { Yellow } & \text { Unchanged } \\ \text { Orange-red } & \text { Orange-red } & \text { " } \\ \text { Violet } & \text { Violet } & \end{array}$

Clear yellow Clear yellow Intense yellow Violet

Violet

Orange
Violet

Red

Yellow
Blue

Red

Yellow

Different values are obtained whether acid be titrated with alkali, or vice versa. This can be helped by titrating to the same end color in both eases, for example, to clear red with phenolphthalein. Values obtained with methyl orange and phenolphthalein are not the same; the difference can be decreased by titrating to the transition color in each case and neglected by titrating to the color of the indicator in water.

Optical.-Fredenhagen (Ann. Fhysik [4] 20, I33) decided that the chief series of the potassium and sodium lines are oxide spectra while the secondary series are due to the metals. Whe green thallium line is also an oxide line. He tried the alkalies and some other elements in the 
ordinary, the carbon monoxide-oxygen and the hydrogen-chlorine flames. In the second flame the same spectra were observed for the alkalies as in the Bunsen flame. They gave no spectra in the hydrogen-chlorine flame, but when the chlorine was cut out the spectra appeared. Calcium and cuprous chloride gave chloride spectra in the hydrogen-chlorine flame. Riesenfeld and Wohlers $(B e r ., 39,2628)$ found that an approximate quantitative determination of the alkaline earths can be made from the brilliancy of the lines of their spectra. With equal amounts the red and green calcium, the orange and blue strontium lines will appear equally bright but the two green barium lines are noticeably darker. With more than twice as much of any one, its lines will appear distinctly brighter. For detection of calcium and strontium the spectral analytical way is more delicate than the chemical, but for barium the chemical is better. A combination solution for the standardization of the spectral apparatus in one series of measurements may be made up of $50 \mathrm{cc}$. of water, Io cc. of $10 \%$ hydrochloric acid, I drop of $10 \%$ sodium hydroxide, Io grams of potassium chloride, 3 grams of strontium chloride, I gram of calcium chloride and 0.8 gram of lithium chloride. This gives the $\mathrm{K} \alpha, \mathrm{Li} \alpha, \mathrm{Na} \mathrm{D}, \mathrm{Ca} \alpha, \mathrm{Sr} \delta$ and $\mathrm{K} \beta$ lines.

Horn (Am. Chem. J., 35, 253) and Horn and Blake (Ibid., 36I, 95, 576) stated that the assumption usually made in colorimetric work that the delicacy of all solutions which are more dilute than those obviously unsuited because of depth of color is practically the same, is not true. It is variable and the ease with which a determination can be carried out varies with the concentration, though a simple relation between them does not exist. Measurements with potassium bichromate solutions showed that the delicacy is greatest at concentrations of 0.004 to 0.008 normal calculated to gram atoms of chromium. The smallest amount of chromium that can be detected in distilled water is 0.000013 gram while 0.00000 I gram causes an easily told difference at concentrations of maximum sensibility. The difference between depth of color of two colored solutions is much more easily detected than the difference between a colored and a colorless one. For colorimetric determinations the concentrations of greatest delicacy should be found experimentally and the conditions of experiment exactly laid down. The different amounts of potassium bichromate and of copper sulphate which cause a noticeable difference in color were determined. The reciprocals of these values plotted as ordinates with square roots of dilutions as abscissae gave a curve with two distinct maxima for the bichromate and one for copper sulphate. The copper sulphate curve corresponded to the first part of the bichromate curve. The delicacy of colorimetric analysis for copper is about thirty times as delicate as for chromium. The delicacy for copper sulphate is inversely proportional to the concentration of copper. Within certain concentrations the percentage errors are constant in all colorimetric analyses. The maximum of delicacy with ammoniacal copper sulphate lies at a concentration of I gram atom of copper in 4996. I liters. In more concentrated solutions a change of 5 per cent. called forth a marked change in color. About the same relation was found to hold for ammonia-free copper sulphate ( 8 per cent.). The delicacy appears to be independent not of color tone but of the nature of the substance in solution. 
De Vecchi ( $Z$. wiss. Mikrosk., 23, 3i2) recommended I and 5 per cent. methyl alcohol solutions of photoxyline as embedding naterial in microscopic work. Visser (Chem. If cethblad, 3, 743) statcd that instead of weighing the nitron precipitates in Busch's deternination of nitric acid they can be compared in height with precipitates from solutions of known content. Instead of 1 Io $11 \mathrm{~g}$. per liter he found in this way Ioo $\mathrm{mg}$. Nitrous, chloric, perchloric, oxilic and salicylic acids give salts with nitron characteristic under the microscope. So also does saccharin after conversion with some clrops of dilute alkali into o-sulphaminobenzoic acid.

\section{Analysis of Inorganic Compounds.}

Noyes (Techn. Quarterly, I6, No. 2; 7 7, No. 3; Chem. News, 93, I34. $146,156,179,189,205,216,226,239,250,262$ ) has published part of his system of qualitative analysis including practically all of the elements. It is worked out with great care with numberless test analyses, checks and notes on the various procedures.

Metalloids, Oxygen, Sulphur.-Bancroft and Hamill ( $J$. Physiology, 34, 306) determined the oxrgen dissolved in physiological salt solutions by boiling the liquid under very low pressure (about 3 mm. of mercury) and catching the gas in a 2 min. wide tube. In such a tube $0.3 \mathrm{cc}$. of gas will cause a bubble roo $\mathrm{mm}$. long. The analysis consists in noting the difference in length of bubble before and after absorption with pyrogallic acid. Wathewson and Calvin ( $A m$. ( hem. J., 36, I I.3) gave a method for the determination of hydrogen peroxide or of ferrous sulplate or other reducing agents in which ferrous ammoniun sulphate and anmonium sulphate in about equal amounts are treated with $5 \mathrm{cc}$ of phosphoric acid and diluted to $50 \mathrm{cc}$. Then $5 \mathrm{cc}$. of at titanium potassium sulphate solution are added and the titration carricd out innmediately with about 0.15 normal hydrogen peroxide to rellow color. Results when the methorl is reversed for hydrogen peroxide are a little lower than those of the permanganate method which is to be expected because permanganate oxidizes the organic matter of the hydrogen peroxide as well. With sodium nitrite the results are too high because the reaction is verv slow near the end point.

Berger (Compt. rend., I43, I I60) determined free sulphur by pouring over an amount of substance containing $0.1-0.2$ gram of free sulphur, Io cc. of fuming nitric acid, adding 0.5 to I gram of potassium bromide, evaporating the liquid after a few minutes to dryness, funing the residue down 2 or 3 times with a few cc. of hydrochloric acid, taking up with water and precipitating as usual with barium chloride.

McFarland and Gregory (Chem. News, 93, 201) detected sulphur in crude iron by mixing 5 grams of sample intimately with 0.5 gram of tartar, wrapping in filter paper and igniting for 15 minutes in a muffe, cooling, breaking up the mass, putting it in an evolution flask with exit tube dipping into an ammoniacal cadminm chloride solution. Boiling hydrochloric acid ( 2 parts acid, $\mathbf{r}$ part water) is put on the mixture. The solution containing the suspended cadmium sulphide is acidified with hydrochloric acid and titrated directly with normal iodine solution. Reinhardt (Stahl u. Eisen, 26, 799) gave is similar method, treating his iron sample with hydrochloric acid in an atmosphere of hydrogen and catching the hydrogen sulphide in an ammoniacal cadmitin solution. 
The precipitate was washed with ammonia, shaken with iodine solution, hydrochloric acid added, and the iodine titrated back with sodium thiosulphate and starch. Gyzander (Chem. News, 93, 2 I3) took up 0.2 gram of pyrites with a mixture of $5 \mathrm{cc}$. of hydrochloric and $\mathrm{r}_{5} \mathrm{cc}$. of nitric acids, evaporated, evaporated again with water and $5 \mathrm{cc}$. of concentrated hydrochloric acid, took up the residue with roo cc. of water, I cc. of concentrated hydrochloric acid and $3 \mathrm{cc}$. of hydroxylamine hydrochloride solution ( $\mathrm{I}$ ounce in $500 \mathrm{cc}$. of water). After the iron was reduced the solution was heated to near boiling, Io cc. of a cold Io per cent. barium chloride solution added dropwise and the barium sulphate determined as usual. Hintz and $\operatorname{Weber}(Z$. anal. Chem., 45, $3 \mathrm{I}$ ) took up their 0.5 gram of pyrites similarly, but removed the iron with ammonia, filtered and washed till filtrate and washwater amounted to $450 \mathrm{cc}$. This was neutralized, using methyl orange as indicator, I cc. of hydrochloric acid (d. I.I7) added, the whole heated to incipient boiling and precipitated with $24 \mathrm{cc}$. of Io per cent. barium chloride solution diluted to IOO cc. heated to boiling and added all at once with vigorous stirring. The washed iron precipitate was dissolved in hydrochloric acid and precipitated again with ammonia, the filtrate and washwater from this treated again with barium chloride, any sulphate formed being added to the main quantity. Raschig ( $Z$. angew. Chem., 19, 33I) determined sulphur in pyrites by precipitation, after its oxidation, as benzidine sulphate, stating that the miethod is more accurate than Hintz and Weber's barium sulphate precipitation.

Bruhns ( $Z$. anal. Chem., 45, 573) determined small amounts of sulphuric acid, especially in waters, by treating $150 \mathrm{cc}$. of the sample in a 200 cc. flask with 5 cc. of a barium chromate emulsion 29.45 grams of potassium chromate and 20 grams of primary potassium carbonate in 750 cc. of water with 48.86 grams of crystallized barium chloride in $25^{\circ}$ cc. of water), pouring off the supernatant liquid and diluting the residual emulsion to $500 \mathrm{cc}$. I cc. of strong hydrochloric acid $(3: 2)$ was added and the whole allowed to stand with some shaking. Thirty minutes after the solution had colored yellow by solution of barium chromate in the hydrochloric acid it was made weakly alkaline with dilute ammonia, diluted to $200 \mathrm{cc}$. and filtered through a dry filter. After shaking, IOO cc. of the filtrate were treated in a glass stoppered flask with some potassium iodide and $5 \mathrm{cc}$. of hydrochloric acid $(3: 2)$ and after 30 minutes titrated with sodium thiosulphate and starch. Using twentiethnormal thiosulphate which has the value of thirtieth-normal here, the number of cc. used multiplied by 1.78 gives the number of mg. of sulphuric acid in $100 \mathrm{cc}$. of water. The result must be corrected by the subtraction of $0.15 \mathrm{cc}$. of thirtieth-normal thiosulphate. Johnson (THIs JoURNAI, 28, I209) determined carbon bisulphide in commercial benzene by conversion into copper xanthogenate, treating $75 \mathrm{cc}$. of benzene with I cc. of saturated alcoholic caustic potash for each O.I gram of bisulphide, adding a weighed amount of bisulphide (0.06 to 0.14 gram) and shaking for $I_{5}$ to 20 minutes. The potassium xanthogenate was dissolved in water by shaking in a separatory funnel and the well washed benzene extracted with $3 / 4$ of the original amount of caustic potash. The extracts and washwater were diluted to $500 \mathrm{cc}$., an aliquot portion weakly acidified with very dilute acetic acid and treated with copper 
sulphate in not too great excess. This was allowed to stand for tis hours with repeated shaking, filtered and the precipitate washed, dried and ignited in porcelain. The results gave a $\mathrm{CuO}: \mathrm{CS}_{2}$ ratio varying from I : I.593 to I: I.825, an average of $I: 1.750$ or whout yo per cent. of Macagno's value 1: 1.931. Seyewitz and Bloch (Bull. sec. chim. [3] 35, 293) determined hydrosulphurous acid in hydrosulphites and their componnds with formaldelyyde by means of their reduction of silver halides, $2 \mathrm{AgCl}-\mathrm{C}$ ${ }_{4} \mathrm{NH}_{3}+\mathrm{Na}_{2} \mathrm{~S}_{2} \mathrm{O}_{4} \cdot 2 \mathrm{H}_{2} \mathrm{O}=2 \mathrm{NaCl}+2\left(\mathrm{NH}_{1}\right)_{2} \mathrm{~S}()_{3}+2 \mathrm{Ag}$. Sulphites, bisulphites and hyposulphites do not do this. If yraldite, $\mathrm{AaHSO})_{2} . \mathrm{CH}_{2} \mathrm{O} .2 \mathrm{H}_{2} \mathrm{O}$, decomposes smoothly with ammoniacal sifer chloride at so? About it times the theoretical anount of silver chloride should be used.

Malogens.-Jannasch and Zimmermann and Jannasch alone (Ber., 39, 106,3655 ) separated the halogens by adding to a solution of the mixture of their compounds in $I_{20}$ to $I_{50} \mathrm{ce}$. of water, $\mathrm{I}_{5} \mathrm{ce}$. of acetic acid and at least 3 cc. of 30 per cent. hydrogen peroxide and distilling off the iodine in 20 to 25 minutes in a current of stean. It was absorked in hydrazine sulphate, concentrated ammonia and water. The contents of the absorption ressels were united, acidifed with $30-40 \mathrm{ec}$ of nitric acid and precipitated cold with silver nitrate. The separation of chlorine and bromine is dependent upon concentration and upon presence of a determined excess of sulphuric acid. With nuth acid hydrogen peroxide sets bromine free even in the cold. It is soparated by means of a current of carbon clioxide by mere warning on a weakly boiling water bath. Rupp and Horn (Arch. Hham., 244, 405) galve a volumetric determination of iodine in the fresence of chlorine and bromine ions. 0.2 to 0.4 gram of the substance was dissolved in $50 \mathrm{ce}$. of water. acidified with $25 \mathrm{cc}$ of dihte sulphuric acid and then about 3 grams of oxalic acid were added. I per cent. potassinu permanganate was added till the liquid shaken upon flatsk wall showed a distinetly viokt color, the mixture allowed to stand 3 hours with oceasional shaking. I gram of potassium iodide was then added and the liberated iodine titrated with tenth-normal thiosulplate. In the presence of chlorine and bromine ions the end point of the permanganate ar!dition fails. io ce. of I per eent. permanganate mav be added when from 8 to $25 \mathrm{c}$. of thiosulphate are required. Then by making a Volharr determination the data are at hand for iodine and chlorine ion separation, iodine and bromine or iodine from chlorine and bromine ions. Ville and Derrien (Bull. soc. chim. [3] 35, 239) detected fluorine in food produets by means of the fact that the absorption spectrum of nethemoglobin is changed by sodium fluoride. The red band $\lambda 6.33$ disappears and Menzie's band ( $\lambda 612)$ appears. Ioo cc. of red wine were craporaled $\frac{1}{2}$ or $\frac{1}{3}$ to remove alcohol, the volume made up again with water, $50 \mathrm{cc}$. of the liquid shaken with I gram of manganese dioxide, filtered, $25 \mathrm{ce}$. of the filt rate treated with 0. I gram of dioxide, I to $1.5 \mathrm{cc}$. of defibrinated blood diluted with 4 volumes of a 1 : roo solution of potassium oxalate added, shaken, filtered and tested. Or ioo ce. of the dealcoholized wine night be treated with 5 cc. of a solution of I part egg albumen and 7 parts of a per cent. potassium oxalate solution, the whole boikd up and filtered after cooling, $25 \mathrm{cc}$. treated with 1 to $\mathrm{i} .5 \mathrm{cc}$ of the reagent blood and tested. Wines with 0.08 to 0. I gram of sodium huorice give Alenzices innel.

Nitrogen, Ihosphoras.-Bornwater (Chem. Heckilad, 3, 30) gave a 
simplified method for determining nitric acid in nitrates. He placed in an $800 \mathrm{cc}$. Erlenmeyer flask about 0.5 gram of nitrate, $200 \mathrm{cc}$. of bromine, 5 cc. of alcohol and 50 cc. of caustic potash (d. I.3), also about 2.5 grams of finely cut aluminum wire. The flask was connected through tube and condenser with a vessel containing standardized sulphuric acid. It was heated slowly till the reaction started and to boiling only after the gas evolution weakened. Busch ( $Z$. angew. Chem., I9, 1329) and Busch and Schneider (Z. ges. Schiess.- u. Sprengstoffw., I, 232) determined the nitrogen content of nitrocellulose by warming 0.2 gram of sample in a flask with $5 \mathrm{cc}$. of 30 per cent. sodium hydroxide and ro cc. of 3 per cent. hydrogen peroxide on a water bath and then boiling over free flame to complete solution. Forty $\mathrm{cc}$. of water and to $\mathrm{cc}$. more of 3 per cent. peroxide were added, the mixture warmed to $50^{\circ}$ and $40 \mathrm{cc}$. of 5 per cent. sulphuric acid allowed to flow into the bottom of the dish from a pipette. The precipitation of the nitric acid was then made with nitron acetate. Busch (Ber., 39, I40I) determined nitrous acid by oxidation with warm neutral 3 per cent. hydrogen peroxide, acidification with 2 per cent. sulphuric acid and precipitation of the nitric acid formed as nitron nitrate (Ibid., 38, 86I). Nitrous and nitric acids together may be determined by titrating the nitrous acid in an aliquot portion with permanganate and in another oxidizing it with hydrogen peroxide and weighing both acids as nitron nitrate. Reichard (Chem. - Ztg., 30, 790) stated that dry arbutin gives with as little as o.00o I gram of nitric acid a yellow color. The color is fairly stable, especially if concentrated hydrochloric acid be used instead of concentrated sulphuric in the test. Forty per cent. caustic potash colors the solution reddish yellow, ammonia weak violet. Berberine and free nitric acid only on warming give a reddish brown substance, in great concentrations almost black, if hydrochloric acid be used to liberate the nitric acid. With sulphuric acid the reaction appears in the cold. It is more delicate than the first.

Artmann and Skrabal ( $Z$. anal. Chem., 46, 5) determined ammonia iodometrically, treating the substance containing it with bromine and alkali, shaking in a closed flask, adding solid potassium iodide, acidifying and titrating the iodine with thiosulphate. Madri (Gaz. chim. ital., $36 \mathrm{I}$, 373 ) criticized the method of Roberto and Roncali (L'industria chimica, 6,178$)$ for the determination of hydrazine with permanganate. They stated that on heating, 5 molecules of nitrogen were set free for 4 molecules of permanganate. Madri said their own results never agreed with their own equation or with the earlier work of Peterson $(Z$. anorg. Chem., 5 , 3). In acid solution the equation is, according to Peterson, ${ }_{7} 7 \mathrm{~N}_{2} \mathrm{H}_{4} \cdot \mathrm{H}_{2} \mathrm{SO}_{4}+\mathrm{I}_{3} \mathrm{O}=\mathrm{I}_{3} \mathrm{H}_{2} \mathrm{O}+7\left(\mathrm{NH}_{4}\right)_{2} \mathrm{SO}_{4}+\mathrm{ION}_{2}+\mathrm{H}_{2} \mathrm{SO}_{4}$. Without the acid the grade of oxidation of the hydrazine increases but does not reach the stage of Roberto and Roncali. Hence the reaction cannot be used for the determination of either permanganate or hydrazine. Potassium bichromate oxidizes hydrazine completely, as has been already pointed out by Purgotti (Gaz. chim. ital., 26 II, 559).

Aronstein (Chem. Weekblad, 3, 283, 493) detected white phosphorus in the presence of much phosphorus sesquisulphide by leading hydrogen or carbon dioxide mixed with air over the substance to be tested. Phosphorescence is given to the gas, disappearing as more air is blown 
in and appearing as the air content becones again less. The pure ses quisulphide shows a similar behavior only at about $80^{\circ}$ or above. The test is delicate to 0.2 per cent. of phosphorus, if its absolute mass is not less than $0.04 \mathrm{mg}$. He criticized Van Iijk's land acetate method and stated that rubbing the carbon bisulphide extract residue in the dark was delicate only to 1.4 per cent. of phosphorus in the sesquisulphide. Van Eijk (Ibid. $3,367,404,623$ ) stated that a test tube containing 250 mg. of phosphorus-free sesquisulphide would light up alsore $70^{\circ}$ while one warmed at same time in the sance water bath containing 0.02 per cent. of phosphorus in the sance amount of sesquisulphicle would do it under $60^{\circ}$. A better test is to distil the meparition with lead acetate; the sesquistlphide is decomposed and an illunination is observed with $0.02 \mathrm{mg}$. of phosphorus or more. To cxclude red phosphoress it is well to extract the mass with carbon bisulphide and to test the residue from evaporation of the bisulphicte for white phosphorus. If this extraction residue be gently rubbed in a dark room, ilimnination is obtained in the presence of white phosphorus. The test is delicate to $0.004 \mathrm{mg}$. The presence of turpentine is disturbing to the phosphorus tests. Aronstein's test is said to be less delicate than these. Schenck and Scharff (Ber., 39, 1522) detected small anounts of white phosphorus by passing a current of air over the warmed substane and leading this to the protective eylinder of an dectroscope. I'hosplorus sesquisulphide causes scarcely any conductivity up to $75^{\circ}$ and none at $50^{\circ}$, but a fraction of a mg. of the white phosphorus will. Teniperatures of $35^{\circ}$ to $55^{\circ}$ are the most suitable. The limit of sensibility is about 0.004 . nng. Siemens (Arb. kais. Gesundheitsant, 24, 264) tested the red phosphorus of commere for white or yellow by extranting 5 grams of the sample with I $50 \mathrm{cc}$. of benzene on a boiling water bath for 1 hour by using a return condenser. After cooling the filtered colution $\mathrm{I} c \mathrm{co}$ of it was treated with I cc. of anmoniacal silver nitrate solution ( $\mathrm{r} .7$ grams of nitrate in $100 \mathrm{cc}$ of ammonia [1.0992]) and shaten. If the color is weak yellow there is no white phosphorus. The color is reddish or dark brown or there is a precipitate in its presence. In I cc. of benzeneo.or $\mathrm{mg}$. of white phosphorus can be detected. Mauricheau-Beaupré (Compt. rend., I42, 1206) gave a qualitative test for phosphorus. A piece of glass tubing 5 to 10 nmm. in diancter is 1)rought into the upper oxidizing part of a hydrogen or acetrlene flante. In the presence of phosphorus the glass is not only etched but gains in weight, while without phosphorus it loses weight and there is no etching. The element may afterwards be determined in the etched part. Phosphine in acetylene in the ratio i: 10000 may be detected. IIydrofluoric acid must be absent. Fricke (Stahl u. Eisen, 26, 279) determined phosphorus in iron and steel by dissolving the sample in nitric acid, oxidizing the phosphorus with permanganate, dissolving the precipitated manganese clioxide in ammonitm chloride solution, evaporating to 30 or $40 \mathrm{cc}$, making weakly acid by nearly neutralizing with ammonia and precipitating warn with molvbdate solution. The precipitate is filtered, washed with cold water till iron is remored, dissolved in standated sodinn livdroxide solution (1 ce. $=0.00025$ gram phosphorus) and the colution titrict lack with sul. phuricacid of the same strength using phenoly ht halein. $\left.2\left[\left(\mathrm{NH}_{1}\right)_{3} \mathrm{PO}\right)_{1} . \mathrm{I}_{2} \mathrm{IOO}_{3}\right]$ $\left.+46 \mathrm{NaOH}=2\left(\mathrm{NH}_{4}\right)_{2} \mathrm{HPO}, \cdots\left(\mathrm{NH}_{1}\right)_{2} \mathrm{MOO}\right)_{1} \therefore 23 \mathrm{Na}_{2}, \mathrm{IOO}_{*} \therefore 22 \mathrm{H}_{2} \mathrm{O}$. 
$2 \mathrm{P}=46 \mathrm{NaOH}=23 \mathrm{H}_{2} \mathrm{SO}_{4}$. Jannasch and Heimann (Ber., 39, 3625) stated that phosphoric acid can be quantitatively volatilized from its salts if an intimate mixture of phosphate and carbon be made first by treating phosphate and sugar solution in a distilling flask with sulphuric acid. The phosphorus is volatilized in a current of chlorine.

Arsenic, Antimony.-Berntrop (Chem. Weekblad, 3, 315) determined the arsenic content of a mirror by oxidation at $60^{\circ}$ with potassium bichromate and sulphuric acid. ${ }_{5} \mathrm{~K}_{2} \mathrm{Cr}_{2} \mathrm{O}_{7}+20 \mathrm{H}_{2} \mathrm{SO}_{4}+6 \mathrm{As}={ }_{5} \mathrm{~K}_{2} \mathrm{SO}_{4}+$ $2 \mathrm{OH}_{2} \mathrm{O}+{ }_{5} \mathrm{Cr}_{2}\left(\mathrm{SO}_{4}\right)_{3}+{ }_{3} \mathrm{As}_{2} \mathrm{O}_{5}$. The excess of bichromate is titrated back with potassium iodide and thiosulphate. The results are somewhat too low because of the formation of some arsenious oxide in the preparation of arsine in spite of efforts to keep air out and the retention of some arsine in the evolution flask, but chiefly because the liquid of the flask remains markedly arsenic-bearing. If this liquid be run again for arsenic and the result added to that of the main determination the method is good. Strzyzowski (Pharm. Post, 39, 677) determined arsenic in animal objects, etc., by heating carefully in a porcelain crucible, I gram of magnesia, Io cc. of the liquid ( 5 to Io g. of half solid matter or I gram of solid broken up and rubbed with Io cc. of water) and 0.5 to $I$ cc. of concentrated nitric acid on an asbestos plate, then over a free flame till after breaking up the residue is pure white. This is taken up with Io cc. of water and 5.5 cc. of 50 per cent. sulphuric acid, filtered from the calcium sulphate and carbon, and the filtrate brought by washing with $12 \frac{1}{2}$ per cent. sulphuric acid to 20 to $25 \mathrm{cc}$. and the magnesium arsenate in solution investigated in the author's Marsh test apparatus. Rosenthaler $(Z$. anal. Chem., 45, 596) determined arsenic acid by the reverse of the iodometric method for arsenious acid. $2 \mathrm{H}_{3} \mathrm{AsO}_{4}+4 \mathrm{KI}+$ ${ }_{4} \mathrm{HCl}=\mathrm{As}_{2} \mathrm{O}_{3}+4 \mathrm{I}+{ }_{4} \mathrm{KCl}+{ }_{5} \mathrm{H}_{2} \mathrm{O}$. The reaction is complete at the end of Io to I5 minutes and the liberated iodine is titrated as usual. Both acids of arsenic may be determined by obtaining the arsenious acid amount first and after oxidation the total amount of arsenic acid.

Low (THIS JoURNAL, 28, I7I5) gave a technical determination of arsenic and antimony in ores in which the sample is taken up with primary potassium sulphate, tartaric and concentrated sulphuric acids. The two sulphides are precipitated by hydrogen sulphide from this diluted and filtered solution, then they are dissolved in potassium sulphide solution. This solution is evaporated with primary potassium sulphate and concentrated sulphuric acid and finally heated till the sulphur and most of the free acid are gone, the cooled residue taken up with water and concentrated hydrochloric acid and the arsenic precipitated with hydrogen sulphide. The filtrate is evaporated again with primary sulphate and sulphuric acid, the cooled residue taken up with water and hydrochloric acid, diluted and titrated with permanganate. The oxalic acid value of the permanganate solution multiplied by 0.9532 gives the antimony value. The arsenic precipitate is dissolved in water containing ammonium sulphide, the solution evaporated with primary sulphate and acid, and the cooled melt taken up with water and boiled. The solution is made weakly alkaline with ammonia, then acid with hydrochloric acid, cooled to room temperature, primary sodium carbonate added and the solution titrated with iodine. Materne (Bull. soc. belg. chim., 20, 46) separated arsenic, antimony and tin by treating the sul- 
phide mixture (containing bivalent tin without tetravalent) with a hot 2 per cent. borax solution, filtering and washing with gradually decras. ing strength of borax solution; the filtrate contained the arsenic. The precipitate was treated with boiling, s per cent. sodiun carbonute solution and filtered hot; the filtrate contained antinony. The tin in the residue was dissolved in 10 per cent. sodiun hrdroxicle. If stamic tin were present instead of stannous, the arsenic was renoved by digestion with cold 2 per cent. borax solution and the residue boiled with 5 per cent. sodium hydroxide solution, dissolving out the tin; the antimony in the residue could then be dissolved in hot 5 per cent. sodium carbonate solution. Treatment of these solutions with hrclrochloric acid or with tartaric acid and ammonium chloride gives the sulphicle in each case. The horax solution is made up of $500 \mathrm{cc}$. of 2 per cent. borax and $20 \mathrm{cc}$. of Io per cent. ammoniun chloride, the sodium carbonate solution of $500 \mathrm{cc}$. of 5 per cent. sodium carbonate and io $\mathrm{ce}$. of ro per cent. ammonium chloride, and the tartaric acid solution of $300 \mathrm{cc}$. of 20 per cent. acid and $150 \mathrm{cc}$. of io per cent. ammonimm chloride. Czerwek ( 2 . anal. Chem., 45, 505) separated antinony fron tin in allors by dissolving in a warm mixture of tartarie and concentrated nitric acids with a little water and precipitating the tin fron this solution leated to incipient boiling by 45 per cent. phosphoric acid. The precipitate was filtered, washed with dilute ammoniun nitrate solution, dissolved in warm annmonium sulphide, reprecipitated with dilute sulphuric acid, filtered, washed again with dilute annnoniun! nitrate, dried and ignited to tin dioxide, oxidizing with nitric acid. The filtrate was neutralized with ammonia, ammonium sulphide added, the solution acidified with acetic acid and the antimony trisulphide filtered warn. The precipitate was washed with dilute ammonium nitrate, dissolved in a large porcelain crucible with ammonium sulphide, the solution evaporated, the residue oxidized with fuming nitric acid and ignited to antimony tetroxide. With other metals present the tin phosphate was washed with 150 to $200 \mathrm{cc}$. of hot normal nitric acid, dissolved in anmonium sulphide, or sodium sulphide if copper were present, and the tin precipitated as above. In the tin filtrate other netals were removed with ammonia and ammonium sulphide and the antimony precipitated by acetic acid.

Carbon, Boron, Silicon.-Aupperle (THis Jourw.1., 28, 858) gave a volumetric method for the determination of carbon in iron and steel which rests on the titration of barium hydroxide into which the carbon dioxide from the combustion of filings of the sample in oxygen has been passed. He stated that the barium hydroxide may be titrated with acid in the presence of barium carbonate without losing carbon dioxide if the acid be run deep into the solution by means of a long capillary tube for any dioxide set free is absorbed again by the hydroxide abure. (Cf. Bruhns, p. 426 Super.) Rosent halerand Türk (Arch. Fharm, 244, 517 ) and the former alone (Ibid., 244, 535) investigated the percentage of clissolved substance absorbed from I per cent. solutions of it in different solvents by 5 times its weight of different kinds of charcoal in the cases of codeine. caffeine, salicine, picrotoxine, gallotannic, crallic and oxalic acids. po. tassium oxalate, indigotine and glucose. The amount and rate of ad sorption are greatest in the case of animal charcoal, great a lio with "flesh" 
and less so with "plantblood" charcoals, and are small with "blood," "limewood" and "sponge" charcoals. They are greatest in aqueous solutions, then in descending order come ethyl alcohol, methyl alcohol, acetic acid, acetone and chloroform. There is relatively less adsorbed in concentrated than in dilute solutions. Adsorption and decolorization are little dependent on the temperature. The more readily a substance is adsorbed the more difficult it is to dissolve it out again. The decolorizing power of charcoals is dependent on their adsorbing power. Charcoal to be used for decolorizing should be carefully purified and used in as small amount as possible. Solutions in solvents other than water and as concentrated as possible are advisable. Substances readily oxidizable must not be decolorized with aninal charcoal. The percentage of a substance adsorbed increases with its molecular weight. Coloring matter in a solution usually has a high molecular weight and its concentration in the solution is usually snall, both being conditions favorable to adsorption.

Castellana (Gaz. chim. ital., $36 \mathrm{I}, 136,232$ ) stated that the green flame test for boric acid is obtained if the substance be mixed with potassium ethyl sulphate and heated with the flame till the first vapors rise and then setting fire to these. $0.5 \mathrm{mg}$. of boric acid may be detected. The characteristic odors of their esters are obtained with a considerable number of organic acids if carefully heated dry with potassitum ethyl sulphate. He stated in reply to Velardi's (Ibid., 36 I, 230) criticism that copper chloride, phosphites and hypophosphites do not interfere with the boric acid color and that the turmeric paper test is not superior to his in delicacy. Fendler ( $Z$. Nahr.-Genussm., II, I37) gave a modification of the turmeric paper test, comparing the color obtained under certain conditions with a variety of standard colors obtained with known amounts of boric acid. Low (THIS JoURNal, 28, 807) found that the turmeric test is extraordinarily sharp if the paper be dried not at $100^{\circ}$ but at ordinary temperatures or $40^{\circ}$ to $50^{\circ}$ in a vacuum desiccator. In I cc. $0.000,00 \mathrm{I}$ gram of boric acid may easily be detected. In the quantitative determination it is not possible to drive all of the boric acid out of water solution with methyl alcohol because the smallest amount of water will hold back considerable acid. All the acid may be driven over by the use of some water-extracting substance like calcium chloride.

Hinden $(Z$. anal. Chem., 45, 332) said that the taking up of silicates after evaporation with hydrofluoric acid may be accomplished by evaporating 4 to 6 times with hydrochloric acid, the bases being converted into chlorides. One gram of substance is moistened in platinum with a little water and evaporated down with Io to I $5 \mathrm{cc}$. of concentrated hydrofluoric acid, the residue taken up with hydrochloric acid (I:I), Io cc. of hydrofluoric acid again added, evaporated and the evaporation repeated about 6 times with o to $20 \mathrm{cc}$. of hydrochloric acid. Complete decomposition is not to be obtained in this way with barium and lead-bearing glasses; here the recommendation is made to filter off the insoluble residue and to treat again with the two acids. Schucht and Möller (Ber., 39, 3693) titrated hydrofluosilicic acid with sodium hydroxide in the presence of methylorange, adding first an excess of neutral calcium chloride solution. $\mathrm{H}_{2} \mathrm{SiF}_{6}+3 \mathrm{CaCl}_{2}+6 \mathrm{NaOH}=3 \mathrm{CaF}_{2}+$ $6 \mathrm{NaCl}+\mathrm{H}_{4} \mathrm{SiO}_{4}+2 \mathrm{H}_{2} \mathrm{O}$. 
Metals, General.-Tarugi and Marchionneschi (Boll. chim. farm. 45, 629) gave some particulars regarding the use of thioacetic acid recom mended by Schiff and Tarugi (Gaz.chim. ital., 24, 551) in qualitative analysis. They stated that it works well. Under pressure in scaled tubes at $90^{\circ}$ it gives complete precipitation of sulphides much more readily than hydrogen sulphide, and in acid concentrations such that under normal circumstances no sulphides would form. The action of thioacetic acid in closed vessels at $90^{\circ}$ is equal to that of hydrogen sulphide at 14.34 atmospheres. Daitz ( $Z$. anul. (hom., 45, j2) criticized the ammonium sulphide group separation of Boetticher (Ibid., 43 , 99), saying that in the separation of cobalt, nickel, iron and mangat nese from aluminum, zinc and chromium by excess of sodium hydroxide and bromine a good deal of nickel and sone cobalt go into solution: also that on treatment of the first four as hydroxides with concentrated hydrochloric acid, evaporation, addition of excess of ammonia, heating to boiling after strong shaking and addition of $2103 \mathrm{cc}$. of hydrogen peroxide and filtering, much nickel and some cobalt are left in the residue while a good deal of iron and manganese go into the filtrate which should contain only complex nickel and cobalt salts. Jannasch and Heimann ( $J, p r$. Chem. [2] 73, 73,488 ) gave some more metal separations by distillation in a current of dry hydrochloric acid gas. Tin distils over away from cadmium at a temperature not above $320^{\circ}$. Bis. muth is separated from cadmium by distilling at temperatures between I $80^{\circ}$ and $350^{\circ}$; bismuth and silver may be easily separated. Antinony distils from lead mixture between $150^{\circ}$ and $250^{\circ}$. Antimony and copper, cadmiun or silver nay be separater. The temperature need in no case exceed $350^{\circ}$. The authors upheld their method against Friedheim's ( $Z$. anal. (hem., 44, 465) criticism.

Alkalies.--Hübener (Chem.-Ztg., 30, 58) in detecting sodium sulphite in thiosulphate made use of the fact that the sulphur dioxide liberated fron the thiosulphate requires twice as much iodine for its oxidation as does the thiosulphate itself. $\mathrm{Na}_{2} \mathrm{~S}_{2} \mathrm{O}_{3} \cdot 5 \mathrm{H}_{2} \mathrm{O}+\mathrm{I}=1 \mathrm{Na}_{2} \mathrm{~S}_{2} \mathrm{O}, \mathrm{NaI}+$ ${ }_{5} \mathrm{H}_{2} \mathrm{O} . \quad \mathrm{Na}_{2} \mathrm{~S}_{2} \mathrm{O}_{3} \cdot 5 \mathrm{H}_{2} \mathrm{O}+\mathrm{H}_{2} \mathrm{SO}_{4}=\mathrm{SO}_{2}+\mathrm{S}+\mathrm{Na}_{2} \mathrm{SO}_{4}+6 \mathrm{H}_{2} \mathrm{O} . \quad \mathrm{SO}_{2}+$ $2 \mathrm{I}+\mathrm{H}_{2} \mathrm{O}=2 \mathrm{HI}+\mathrm{H}_{2} \mathrm{SO}_{4}$. One determination is made direct, with iodine, another by passing the sulphur dioxide erolved in an atmosphere of carbon dioxide through an excess of iodine and titrating back. These two values by suitable calculation give the amounts of sulphite and thiosulphate in the sample. He found in a sample supposedly go per cent. pure, 92.87 per cent. thiosulphate, 3. I I per cent. sulphite and 2.66 per cent. sulphate, the last figure representing sodium sulphate corresponding to the barium sulphate difference of the totally oxidized san. ple and that calculated to correspond to the sulphite and thiosulphate. Cormimboeuf (Ann. chim. anal. appl., II, I30) determined potassimm chloride in potassium bromide by precipitating both as silver salt and weighing. 2 grams of pure potassium bromide should give 3.1596 grams of silver bromide while 2 grams of potassium chloride should weigh 3.8523 grams as silver chloride. He assumed 1 per cent. of potassium chloride would increase the weight of the silver bromide by 0.006027 gram and gave a table for the chloride content of the bromicle. Pajettit (Gaz.chim. ital., 36 II, x 50, 298) stated that the soltubility of potassium or potassium and sodium persulphate is increased by the presence of 
sodium sulphate and decreased by potassium sulphate, the solubility coefficients per IOo cc. at $12^{\circ}$ being for saturated solutions of sodium sulphate 5.982 , of primary sulphate 8.72 , of potassium sulphate 0.792 , of primary sulphate 0.329 . There is direct proportionality to the greater or less solubility of the sodium or potassium. salt. The solubility of the persulphate in sodium salt solutions is a function of their concentration of sodium. Hence the greater solubility in the presence of sodium salts is probably due to chemical action. $\mathrm{K}_{2} \mathrm{~S}_{2} \mathrm{O}_{8}+\mathrm{Na}_{2} \mathrm{SO}_{4}=\mathrm{Na}_{2} \mathrm{~S}_{2} \mathrm{O}_{8}+$ $\mathrm{K}_{2} \mathrm{SO}_{4}$. On this ground he criticized Tarugi's (Ibid., $34 \mathrm{I}, 324$ ) method for the determination of potassium. Schlicht (Chem.-Ztg., 30, 1299) observed that sodium phosphomolybdate solution gives a yellow precipitate when heated with potassium salts acidified with nitric acid and makes a good test for potassium.

Beryllium, Magnesium, Alkaline Earths.-Glassmann (Ber., 39, 3366, 3368) gave a quantitative separation of beryllium and aluminum, neutralizing the hydrochloric or sulphuric acid solution of the oxides approximately with sodium carbonate and adding excess of sodium thiosulphate, then boiling till the odor of sulphur dioxide disappears and heating for $\frac{1}{2}$ hour on the water bath. Beryllium remains in solution as sulphite or basic sulphite. The aluminum hydroxide and sulphur precipitate is washed and ignited. The excess of thiosulphate in the filtrate is decomposed with hydrochloric acid and the beryllium precipitated with ammonia or according to Glassmann's method with potassium iodide and iodate, which according to Friedheim (Ibid., 39, 3868) was first described by Joy in 1864 and later by Zimmermann in 1887 . Parsons and Barnes (THIs JourNAL, 28, 1589 ) separated beryllium from aluminum and iron by neutralizing the chloride solution as nearly as possible with ammonia, treating the cold solution with Io grams of primary sodium carbonate, heating the mixture as rapidly as possible to boiling and boiling for I minute. The beaker is set in cold water to cool, the precipitate filtered and washed with hot water and dissolved on the filter in as little hydrochloric acid (I:I) as possible, diluting to roo $\mathrm{cc}$. in the original beaker. This solution is neutralized with ammonia and the precipitation repeated. The filtrate and washings are neutralized with concentrated hydrochloric acid, the precipitate dissolved, the solution boiled to drive out carbon dioxide and the beryllium precipitated by ammonia as the hydroxide, this washed with ammonium acetate solution, dried, ignited and weighed as the oxide. The aluminum hydroxide precipitated is dissolved in hydrochloric acid, reprecipitated with anmonia, ignited and weighed. The iron separation is the same.

Grimbert (J. pharm. chim. [6] 23, 237) carried out the Schlagdenhauffen reaction for magnesium by treating ro $\mathrm{cc}$. of the solution with $5 \mathrm{cc}$. of Io per cent. potassium iodide and 2 to 3 drops of a concentrated sodium hypochlorite solution. In the presence of magnesium a reddish precipitate looking like ferric hydroxide is obtained. The test is delicate to $\mathrm{r}$ : 2000; the solution must never be acid. Bellier (Ibid., [6] 23,378 ) treated the magnesium solution with a solution of iodine in potassium iodide and then dropwise with dilute sodium hydroxide. With more than 0.02 per cent. of magnesium a relatively abundant reddish brown precipitate is obtained; with 0.005 per cent. a reddish brownyellow color. A delicacy of $I: 20000$ is claimed for this modification. 
Ammonium salts, acids and alkalies prevent the reaction completely; lime lowers its delicacy somewhat. The precipitate is perhaps a mixture of magnesium oxide and iodine. Berju ( $\mathrm{hcm}$. -Zig., 30, 823) determined small amounts of magnesium indirectly by weighing the phosphoric acid of magnesium ammonium phosphate as $\mathrm{I}_{2} \mathrm{O}_{5} .24 \mathrm{AoO} \mathrm{O}_{3}$.

Löb (Ibid., 30, 1275) found that bariuril dioxide could not be titrated with permanganate in the presence of sulphuric acid hecause the barium sulphate apparently occluded some of the substance, but it might be in the presence of hydrochloric acid and manganese sulphate. The results of the method wete compared with these of an iodometric one, the barium dioxide in hydrochloric acid solution being ircated with potassium iodide solution and the iodine titrated back with thiosulphate. A neutral or weekly ammoniacal solution of the alkaline earth was treated by Benedict (THIS JourNil, 28, 1596) with its rolume of 5 times normal hydrochloric acid, then 2 to $3 \mathrm{cc}$. of saturated potassimn iodate solution. No precipitate indicates the absence of barjun, an innmediate one shows considerable and a slow one little barium or considerable strontium. The filtrate is tested with a little nore than an equal volume of saturated anmonium sulphate solution and heated to boiling; a white permanent precipitate indicates strontiums. Another portion of the original solution is allowed to stand with twice its volume of saturated potassium iodate solution for 20 I minute after shaking, then the filtrate is tested with i its volume of ammonium oxalate for calcium. Caron and Raquet (Baill. soc. chim. [3] 35, IO6 I) precipitated barium as chromate from the alkaline carth mixture, then after making the filtrate alkaline again with ammonia threw out the strontim with alcohol. The calcium was tested for with potassium ferrocynicle solution.

Iron. Aluminum.-Komar (Chem.-Ztg., 30, 15, 31) obtained the salt IeH $\left(\mathrm{SO}_{4}\right)_{2} \cdot{ }_{4} \mathrm{H}_{2} \mathrm{O}$ by evaporation of a solution of ferric strlphate (prepared by the oxidation of a solution of ferrous sulphate in sulphuric acid by means of nitric acid or by electrolysis) from a strlphuric acid content of $400 \mathrm{cc}$. of the monohydrate per litcr to a concentration of $45^{\circ}$ to $50^{\circ}$ Baume. The compound is partly easily soluble in water, partly difficulty. The at first cloudy and finally clear green solution reacts weakly acid and does not reduce permanganate. Hy heating at $90^{\circ}$ to $100^{\circ}$ the compound destroys paper and smells of sulphuric acid; on gontly leating in a crucible sulphur trioxide and ferric oxide are obtaineci. Iron and zine may be separated by conversion into sulphates, dissolving these in sulphuric acid (400 ce. of monohydrate per liter [d. 1.3 to 1.4 ]), eraporating this solution to dryness and igniting the residue to constant weight over the burner. The zine sulphate decomposes only at about $700^{\circ}$ and may be extracted with water. Rupp and Foril (Arch. Iham., 244, 57I) modified Rupp's (Ber., 36, 164) method for the titration of ferrous salts with alkali hypoiodite, using canstic potalsh in place of sodium potassium tartrate as the hydriodic acid binding agent. Ferrous iron is instantly oxidized to ferric by the measured excess of tenth-normal iodine in the presence of nornal or 5 per cont. caustic potash. The solution is then acidified with acctic or better with oxalic acid and the iodine excess titrated with thiosulphate.

Moody (Am. J. Sci. [4] 22, $48_{3} ; Z$. anorg. Chem., 52, 286) gave an 
iodometric determination of basic alumina and free sulphuric acid in aluminum sulphate and alums. The iron is determined in aliquot portions before and after reduction witt zinc, and any zinc by electrolysis from acetate solution. A portion is boiled with potassium iodide-iodate mixture in a suitable apparatus and the iodine collected in a receiver containing potassium iodide. After slightly acidifying with sulphuric acid the iodine is titrated with thiosulphate. The precipitate formed in the flask contains besides alumina, ferric and zinc oxides which are determined in the usual ways. I molecule of alumina requires 6 atoms of iodine, $x$ of ferric oxide 6 of iodine, I of ferrous oxide 2 of iodine, 5 of zinc oxide 8 of iodine, I of ammonium I of iodine and I of sulphuric acid 2 of iodine. The decomposition of zinc sulphate is abnormal. $\mathrm{I}_{5} \mathrm{ZnSO}_{4}+20 \mathrm{KI}+{ }_{4} \mathrm{KIO}_{3}+\mathrm{I}_{2} \mathrm{H}_{2} \mathrm{O}={ }_{3} \mathrm{Zn}_{5}(\mathrm{OH})_{8} \mathrm{SO}_{4}+\mathrm{I}_{2} \mathrm{~K}_{2} \mathrm{SO}_{4}+24 \mathrm{I}$. The total iodine less the sum calculated to correspond to the single sulphates gives the iodine difference; if this be positive the, mixture contains free acid, if negative, free alumina.

Cobalt, Nickel, Manganese, Zinc.-Alvarez (Ann. chim. anal. appl., I I, 445 ; Chem. News, 94, 306) stated that the blue color pointed out by Donath in I 901 as obtained when solid caustic potash or soda or very concentrated alkali solution was added to cobalt solutions is obtained also when barium hydroxide, calcium chloride or other water-extracting substance is added. I drop of I : 100 cobalt solution added to boiling concentrated alkali solution will give the reaction, which takes place in the presence of nickel. Grossmann and Schück (Ber., 39, 3356) gave a new test for nickel, treating a solution of dicyanodiamine with a little hydrochloric acid, heating to boiling, adding the nickel salt, then caustic potash solution and obtaining a yellow crystalline precipitate of nickel dicyanodiamidine $\left(\mathrm{Ni}\left[\mathrm{C}_{2} \mathrm{H}_{5} \mathrm{ON}_{4}\right]_{2}, 2 \mathrm{H}_{2} \mathrm{O}\right)$ in needles arranged in star shapes. They are immediately soluble in potassium cyanide, but not in boiling caustic potash solution, and are sparingly soluble in water and ammonia. Cobalt forms no analogous compound. Reichard (Chem.2 tg., 30, 556) stated that if powdered dehydrated nickel salts of mineral acids are heated with an equal amount of fully dry methylamine hydrochloride in porcelain the color becomes deep dark blue. This color disappears on cooling, leaving a dirty gray-yellow, solid mass which soon deliquesces. It becomes blue again on heating and decolorizes on cooling. The color is shown with $0.1 \mathrm{mg}$. of nickel. Cobalt salts similarly heated yield deep blue oily drops which do not lose their color on cooling.

Funk ( $Z$. anal. Chem., 45, 562) observed that iron and manganese sulphides dissolve very easily in dilute acids, but in the presence of ammonium salts nickel sulphide and even more easily cobalt sulphide dissolve, too. At ordinary temperature nickel and cobalt sulphides are not dissolved by a little dissociated acid like formic but in separations they dissolve and some iron sulphide remains. Manganese sulphide dissolves except for traces. Jannasch and Gottschalk (J.pr. Chem. [2] 73, 497) precipitated manganese from ammoniacal solutions by means of oxygen rich in ozone. Small amounts of manganese can be precipitated by slow passage of the ozone through the ammoniacal solution. Large amounts are managed by adding the manganese solution dropwise to IOO cc. of strong ammonia through which a vigorous ozone current is 
passing. The precipitate is hydrated manganese dioxide. Manganese may be separated from sodium, calcium and zinc in this manncr by one precipitation. Magnesium, nickel, cadmium and copper each require a repetition of the precipitation in order that the nangancse may be free from them; the precipitate is dissolved in hydrochloric acid containing hydrogen peroxide. The separation of manganese and cobalt failed. Tarugi (Gaz. chim. ital., $36 \mathrm{I}, 332$ ) gave a test for manganese and an new method for the formation of glycerose. Manganese hydroxide dissolves in glycerol and such a solution colors itself red by oxidation through air or more quickly through oxygen or sodium hypochlorite. The color intensity depends only on the amount of ninuganese present. 0.00001 gram of manganese can be detected. Cobalt and copper interfere only with amounts of less than i per rooo. Glycerol is convered into glycerose through sodium hypochlorite by i drop of $\mathrm{r}: 1000$ cobalt chloride solution. 50 ce. of glycerol, 2 ce. of 5.9: 1000 cobalt chloride and $10 \mathrm{cc}$. of 50 per cent. caustic soda put all at once into i $50 \mathrm{cc}$. of sodium hypochlorite ( 7 per cent. active chlorine) gave on cooling in ice, 18 per cent. of glycerose.

Bertrand and Javillier (Compt. rend., I43, g0o; Bull. soc. chim. [4] $\mathbf{r}, 63$ ) gave a method for the precipitation of zinc, treating a solution containing zinc and a sufficient amount of line with excess of ammonia and heating to boiling, the calcium zincate coming out in microscopic crystals. It is difficultly soluble in excess of lime and may be used for quantitative work. The zincate is mixed with carbonate; the precipitate is dissolved in hydrochloric acid, the solution evaporated to dryness, the residue taken up with some water, the lime precipitated with ammonium oxalate and the filtrate evaporated and ignited with sulphuric acid to zinc sulphate. Less than 1 part of zine in 500,000 of 50 lution can be detected. A zine test was given also by Bradley (see under copper).

Mercury, Silver.-Rupp (Ber., 39, 3702) gave a volumetric determination of mercury, adding to the mercuric salt solution (about 0.2 gram in 25 to $50 \mathrm{cc}$.) I to 2 grams potassium iodide so that the precipitate first formed dissolves, making alkaline with catustic potash or soda, then adding with shaking, a mixture of 2 to $3 \mathrm{cc}$. of 40 per cent. formaldehyde and Io cc. of water. The nixture is acidified with acetic acid to distinct odor, an excess of tenth-normal iodine solution $(2.5 \mathrm{cc}$.) added, the metallic mereury brought into solution by shaking and the execss of iodine titrated with tenth-normal thiosulphate. Utz (I'harm. Post, 39, 785) modified his 1905 method of determining sublimate in dressing materials to conform to this mercury determination of Rupp's. Scidell ('lins JoURNAL, 28, 73) determined mercury and iodine in antiseptie soaps by treating the soap sample with $150 \mathrm{cc}$. of 95 per cent. alcohol and 3 to 5 cc. of concentrated hydrochloric acid, warming the mixture and adding gradually small amounts of water till the whole is in solution. Mercury is precipitated as sulphide, filtered into a Gooch crucible and washed with 95 per cent. alcohol. The filtrate freed from fat may be shaken in a separatory funnel with chloroform and a few clrops of nitrous acid and the iodine in the chloroform determined by titration with thiosulphate. Goldschmidt (Z, anal. Chem., 45, 87) stated that silver is precipitated quantitatively as a black powder, if cobalt foil be put into 
boiling silver salt solutions and that it may be weighed. Gold is likewise thrown out of boiling solutions by nickel as a brown powder.

Copper, Cadmium, Bismuth.-Bradley (Am. J. Sci. [4] 22, 326) observed that the blue color of "logwood hematoxylin" and copper salts

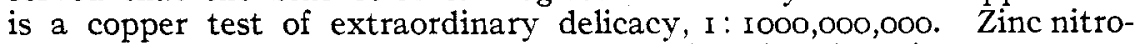
prusside is crystalline and may be detected under the microscope even in the presence of amorphous precipitates, the reaction being much more delicate than the common precipitation tests for zinc. Rhead (Proc. Chem. Soc., 22, 244; J. Chem. Soc., 89, I49I) determined copper with the aid of standard titanium trichloride solution in the presence of potassium thiocyanate. Cupric salts are reduced and the copper precipitated in the presence of sulphuric or hydrochloric acid as cuprous thiocyanate. A ferrous salt is added to sharpen the end-point. The cupric salt oxidizes an equivalent amount of the ferrous salt and the red color of ferric thiocyanate appears. The color disappears at the end of the reaction. The titration must be carried out below $30^{\circ}$ and as rapidly as possible. Nitric acid must be absent. Ferric iron and cupric copper may be determined together and the iron subtracted after separate determinations. The titanium trichloride is standardized by means of a ferric salt solution obtained by the oxidation of a ferrous salt with permanganate.

Goldschmidt ( $Z$. anal. Chem., 45, 344) observed that cadmium is quantitatively precipitated from boiling salt solutions in aluminum dishes in the presence of traces of chromium and cobalt nitrates. The catalyzing agent is aluminum. Other metals can be used for the quantitative determination by catalysis. Moser (Ibid., 45, 14) found that bismuth precipitated as phosphate would carry down some cadmium in the separation of bismuth from copper and much cadmium and that the cadmium is hard to remove. It is not easy to make a second precipitation of the bismuth phosphate because of its insolubility. The method is good for the determination of bismuth alone but as a separation has no advantages over the ordinary one.

Uranium, Vanadium, Molybdenum, Tungsten.-Finn (THIs Journal, 28, I 443) separated uranium and vanadium, after solution of the mineral sample in sulphuric acid, by precipitating twice with excess of sodium hydroxide solution, boiling each time, acidifying the united filtrate and washwaters with sulphuric acid, adding ammonium phosphate and making alkaline with ammonia. The filtrate containing vanadium is acidified with sulphuric acid, reduced with sulphur dioxide till the solution is blue and titrated hot with permanganate. The uranium precipitate $\left(\mathrm{UO}_{2} \mathrm{NH}_{4} \mathrm{PO}_{4}\right)$ is dissolved in sulphuric acid reduced with zinc and the filtrate titrated with twentieth-normal permanganate at $60^{\circ}$. The iron factor multiplied by $\mathrm{I} .63$ I gives vanadium pentoxide, by 0.9159 vanadium, by 2.567 uranous uranic oxide and by 2.133 uranium. Gilbert $(Z$. öffentl. Chem., 12, 263) determined molybdenum in glance by extracting the trioxide with ammonia, after roasting in air, and igniting to constant weight. The small amout of molybdenum left in the roasted ore is obtained by fusing with potassium and sodium carbonates, taking up with acid, reducing with zinc and titrating with permanganate.

Von Knorre (Stahl u. Eisen, 26, 1489) modified his earlier method for determining tungsten in steel. The steel is dissolved in hydrochloric 
acid with exclusion of air and without filtering the acid is neutralized with sodium carbonate; after cooling, ro ce. of approximately tenthnormal sulphuric acid or alkali sulphate and 40 to $60 \mathrm{cc}$. of benzidine solution are adcied. The precipitate of tungsten, benzidine tungstate and sulphate is filtered, washed with dilute benzidine solution and ignited in platinunn. The iron bearing ungsten trioxide is taken up by fusion with sodiun carbonate, tile melt extracted with hot water, the iron oxide filtered ont and the solution acidified with hydrochloric acid (using methyl orange). After addition of io $\mathrm{cc}$. of sulphuric acid the tungsten trioxide is precipitated with benzidine solution, filtered, washed as before, ignited and weighed as trioxide. Watts (Western Chemist and Metullurgist, July, 1906; Chom. News, 95, 19) determined tungstic acid in natural and concentrated tungsten ores by taking up I gram with $50 \mathrm{cc}$. of lydrochloric and $15 \mathrm{cc}$. of nitric acid, both concentrated, heating to near builing for thours in a covered beaker. This is concen trated to 10 to $15 \mathrm{ce}$., $50 \mathrm{ec}$. of hot water anch $5 \mathrm{cc}$. of hydrochloric acid aclded. lungsten trioxide is separated from silica by weak ammonia containing some ammonium chloride. The ammoniacal solution is evaporated and the trioxide ignited and weighed.

Gold, Platinum Cinotp, Tin.--Donau (Monatsh., 27, 59) described a new method for the determination of the metals, especially gold and palladium, through conductivity meastrements. The gold solution is put into at $U$ conductivity measuring tube, reduced by carbon monoxide and the maximunu effect of the carbon monoxide measured. The in. crease of conductivity (d) is affected somewhat by acid content, $d$ :-: $0.000476+0.2771-101^{2}(1=$ initial conductivity $)$ Each gold content ( $z$ mg. per roo ce.) with definite initial conductivity $\left(y \cdot 0^{-4}\right)$ which is different for the different amounts of hydrochloric acid corresponds to a certain increase in conductivity $\left(x, 10^{--1}\right)$. 'The $x y$ ' function being nnknown, an empirical function is assumed and an equation obtainer by the metlod of lexist scuares. $z=1.76 x-0.0237 x y+0.0138 x^{2}-2$ $0.0011 x^{2} y^{\prime}+0.0007 .38 x y^{\prime 2}$. The gold content cat1 also be obtained from graphic representation. The palladium determination is simpler, the conductivity is only insignificantly affected by the frec acid content and is nearly proportional within certain limits to the palladium content. The number of mg. of palladium per soo ce. is given by multiplying $1.21 \mathrm{~W}$ $10^{-4}$ by the incresse in conductivity. The mean error here is 0.3 per cent. IIaxson (Am. J. Sci. [4] 21, 270;Z. unorg. Chem., 49, 172) made satisfactory colorimetric determinations of gold in small amounts, preparing his red colloidal solution by mixing gold chloride and saturated aqueous acetylene solutions. The content of such solutions was determined gravimetrically and different concentrations were prepared by cxact dilution. First a Gallenkampf then a P'enfield colorimeter was used. The least determinable quantity was $0.000,0 \mathrm{I}$ gram; the largest amount was 0.0008 with an error of $0.000,06$. Petersen ( $Z$. anal. Chem., 45, 342 ) instead of the usual separation of gold, platinum, antimony and arsenic in the hydrogen sulphide group, precipitated all the metals of the group and some cobalt and nickel from weakly acid solution with zine turnings. After wirming for thour the precipitate was washed and warmed with rlilute hydrochloric acid; cadminm, tin and some cobalt dissolved. The residte was washed, then boiled with dilute nitric 
acid; mercury, lead, bismuth, copper, nickel dissolved leaving gold, platinum, antimony and some antimonic acid. This residue was ignited with I to 2 parts of ammonium nitrate and 5 parts of ammonium chloride in porcelain; antimony volatilized as chloride. The residual gold and platinum were dissolved in aqua regia, and detected through concentrated ammonium chloride or sulphur dioxide or alkaline hydrogen peroxide. Arsenic, antimony and zinc must be tested for in special portions. The original solution was tested for zinc by precipitating with sodium carbonate, dissolving the precipitate in hydrochloric acid, passing in hydrogen sulphide and decomposing with excess of sodium acetate; white zinc sulphide was precipitated. Orloff (Chem.-Ztg., 30, 7I4) observed that hydrogen peroxide seems to dissolve osmium and osmium hydroxide to a marked degree to osmium tetroxide. Histological specimens blackened by osmic acid are completely decolorized by hydrogen peroxide. From mixtures of the platinum metals obtained by reduction with zinc or magnesium the peroxide dissolves only osmium. Silver iodide rapidly blackens with palladium chloride or bromide, forming a mixture of palladium iodide and silver chloride. Soluble alkali and alkaline earth iodides form insoluble precipitates with salts of other platinum metals, hence a potassium iodide solution may be used only with certain precautions to separate palladium from the others. But freshly precipitated silver iodide changes only palladium chloride to black iodide. Thompson and Miller (THIs Journal, 28, i I I5) determined melting points, cooling curves, microstructure, densities and electrical conductivities of platinum silver alloys containing about ro, 20, 30,40 , and 50 per cent. platinum. They concluded that it is not possible to separate platinum from gold, iridium, etc., by alloying with silver and dissolving in nitric acid, that platinum alloys of more than 20 per cent. platinum cannot be completely separated by concentrated sulphuric acid, and that the irregular results obtained from treating these alloys with nitric acid are caused apparently by the existence of platinum silver compounds. They analyzed the alloys by treating them hot with concentrated sulphuric acid in two portions, diluting, filtering and washing out the silver, then igniting the residue in porcelain. This residue was taken up in aqua regia and evaporated nearly to dryness with nitric acid. The solution was diluted and the silver precipitated with sodium chloride solution. The precipitate was washed free from chlorine, dissolved in ammonia and reprecipitated with nitric acid. From the solution in sulphuric acid the silver was precipitated after dilution either as sulphide or as chloride.

Reichard (Pharm. Centrh., 47, 39I) gave a new reaction for tin, treating a little finely pulverized uric acid with some drops of stannic chloride solution, then adding concentrated sodium hydroxide to the mass dropwise with stirring till nearly all is dissolved and heating. A gray to intense black fleck is formed. Stannous compounds do not give the reaction, neither do arsenic or antimonic acid. Lead and cadmium do not give it. Copper hydroxide gives a black on heating without the uric acid, owing to the formation of copper oxide. Mercuric chloride gives a reddish brown compound. Bismuth gives the same reaction as tin but the precipitate is insoluble in sodium hydroxide, 0.000 I gram of tin may be detected. Nitric and hydrochloric acids destroy 
the black residue only slowly and incompletely, sulphuric acid immediately.

Misccllanous.-- Rimini (Atti uccut. Lincei [.5] I5, II, 320) stated that both Riegler and Ebler have overlooked his work on hydrazine volumetric methods. He modified his iodometric method by carrying out the determination in alkaline solution, thus avoiding the separation of

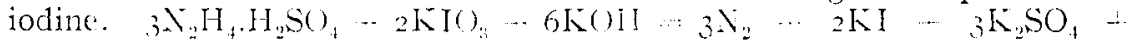
$\mathrm{I}_{2} \mathrm{H}_{2} \mathrm{O}$. Instead of Libler's mereury method he proposed to add to a concentrated solution of hyclazinc sulphate after neutralizing, using methyl orange as indicator, a certain excess of half-normal sodiun hy. droxide, then the mercury salt solution and llen to heat. The solution was brought to definite volume and the excess of sodium hydroxide determined in an aliquot portion or in the filtrate with half-normal acid. $\mathrm{N}_{2} \mathrm{H}_{1} \cdot \mathrm{H}_{2} \mathrm{SO}_{1}+2 \mathrm{H}_{\mathrm{gCl}}+{ }_{5} \mathrm{NaOH}-\mathrm{NaCl}-\mathrm{NaHSO}_{4}+\mathrm{Hg}_{2}+\mathrm{N}_{2}+$ ${ }_{5} \mathrm{H}_{2}(\mathrm{O})$ Pannatni's method for potassium perstlpliate gives too high results. Rimini adred to a netrtral solution of persulphate a solution of hydrazine sulphate nentralized with canstic potash, then shook this up with titrated caustic potash and cletemined the excess of alkali after 5 minutes. $2 \mathrm{~K}_{2} \mathrm{~S}_{2} \mathrm{O}-\mathrm{N}_{2} \mathrm{H}_{1}, \mathrm{H}_{2} \mathrm{SO}, 5 \mathrm{KOH}-\mathrm{N}_{2}+{ }_{5} \mathrm{~K}_{2} \mathrm{SO}_{4}+5 \mathrm{H}_{2} \mathrm{O}$.

Puschin (J.ms, hhes-chem. Fo, $38,-64$ ) gave a quantitative separation of tin from manganese, ferrous iron and chrominm by electrol ysis. Biralent iron and nunganese may be scparated like cobalt and nickel from tin (Ibirl. 37, 828). Trivalent manganese and chrominum may also be separated casily from tin. A satisfactory separation of ferric iron and tin was not obtained.

\section{Analysis of Organic Compounds.}

General, Hydroarbons, Donatives.-. Alvarez (Chem. Neas, 94, 297: Ann. chim. anul. appl., I2, o) observed that hydrated sodium peroxide, the color reagent for polyphenols, gives characteristic colors with some other compounds when 0.2 to 0.3 gram of peroxide and 0.05 to 0.1 gram of substance are treated with, $5 \mathrm{ce}$. of alcohol, then after 4 to 6 minutes with $y_{5} \mathrm{cc}$. of water. Finodine gives an intense lighn red. changed to yellow with acetic acid; cirvsarobin a wine color, vellow with acetic acid, 1, 2 dihydroxyanthraquinone bluc-viokt, yellow with acids (blowing on the blue-violet solution causes it to tum red at edges); alizarin violet, orange with acids: 1,2,-trihydroxyanthraquinone intense red-riolet in alcohol. cherry-red in water; chrrsophanic acid cherry-red in alcohol, lighter red in water; rosolic acid intense purple; purpurin alizarin-red; anthragallol almost black dark bluc; dihydroxyquinone brown in al. cohol, red in water, and rlagic acid brown-black in alcohol, yellow in water. Craefe (Chem. Ror. Fot.. u. How Ind., 13, 30) stated that carbon tetrachloride surpasses all other ordinary solvents in the power to dissolve paraffin, for example at $20^{\circ}$ of a parafin of melting point $5.3 .5^{\circ}$ 1 ce. of ethylacetate, dissolves $I, I$, of acetone $1,2,96$ per cent. alcohol I.9, ether 83.4 , petroleum ether 200 , ligroin 244 , chloroform 246 , benzene 285 and carbon tetrachloride $3 \mathrm{I} 7 \mathrm{mg}$. Carboil tetrachloricle also gives good results in the fractional precipitation of different paraffins. Ni cloux (Compt. rint. 142, 16.3; Bull. soc. chim. [3] 35, 321) determined small amounts of chloroform in air or in blood or an aqueous liquid by heating $60 \mathrm{ce}$. of alcoholic chloroform solution with io cc. of io per cent. itlcoholic caustic potash for 30 to 4.5 minutes. The reaction $\mathrm{CHCl}_{3}$ 
${ }_{4} \mathrm{KOH}={ }_{3} \mathrm{KCl}+\mathrm{KHCO}_{3}+\mathrm{H}_{2} \mathrm{O}$ is quantitative. Fifteen cc. of water are added after cooling, the solution is neutralized with sulphuric acid, using phenolphthalein, and titrated with silver solution and potassium chromate as indicator. The error is I to 2 per cent. To determine chloroform in air the air is drawn through 2 wash flasks containing 96 per cent. alcohol at the rate of 2 liters per hour. In blood the five-fold volume of 80 to 95 per cent. alcohol acidified with 0.25 gram of tartaric acid is added, then Io cc. of 95 per cent. alcohol, $\frac{1}{3}$ of the liquid is distilled off and the rest of the determination carried out as above.

Reichard (Pharm. Centrh., 47, 309) observed that phenanthrenquinone dissolved in concentrated excess of primary sodium sulphite solution and warmed gave on cooling a colorless crystal mass which on standing for some weeks about $2 / 3$ liquefied again. At the same time there formed at the upper edge of the crystal mass a red to red-brown ring, changing soon to gray and finally increasing in volume till the whole mass was colored gray, while the liquid was colored clear green. Dupré (The Analyst, 3I, 213) determined moisture in a substance containing other volatile material by putting the substance in layers in a tube $1 \mathrm{~cm}$. wide and 12 long 'yetween layers of fine sand and calcium carbide, connecting the tube witli a nitrometer filled with saturated sodium chloride solution. On warming on a water bath acetylene was obtained. One cc. of acetylene corresponds to 0.001725 gram of water. The method can be used on a substance like cordite. Raikow and Ürkewitsch (Chem.$Z t g ., 30,295$ ) observed that solid pulverized caustic potash gives a brown color with nitrotoluene and nitrobenzene, weaker with the latter. Pulverized caustic soda does not act at ordinary temperatures with nitrobenzene (distinction from caustic potash) but gives a yellow-brown color with nitrotoluene. The reaction is more delicate when gasoline is used as a solvent ( $\mathrm{I}$ cc. for 0.5 gram of caustic soda). In I cc. of gasoline solution, $0.0025 \mathrm{cc}$. of nitrotoluene can be detected. To detect toluene in benzene both are converted into nitro compounds and tested. An approximate quantitative determination can be made by comparing the brown color with that caused by known amounts of nitrotoluene in gasoline solution. Alkali hydroxides in this reaction are effective in the order of the atomic weight of their metals, lithium hydroxide weakest, then those of sodium, potassium and rubidium.

Alcohols, Phenols.-Blank and Finkenbeiner (Ber., 39, I 326) determined the methyl alcohol in formaldehyde solutions by putting I gram of the solution into $50 \mathrm{cc}$. of twice normal chromium trioxide and $20 \mathrm{cc}$. of 98 per cent. sulphuric acid, diluting after I 2 hours to I liter, adding a little potassium iodide to $50 \mathrm{cc}$. of this solution and titrating back with tenth-normal thiosulphate. Methyl alcohol $=32(a-b)$ IOO/48 per cent., where $a=0.8$ gram (the amount of oxygen used $-0.016 \times$ number of cc. of thiosulphate used) and $b=$ the oxygen needed for the oxidation of the formaldehyde. The latter is calculated from the formula $32 \times \frac{\text { per cent. content }}{30 \times \text { roo }}$. Fendler and Mannich (Arb. Pharm. Inst.

Univ. Berlin III, I) determined methyl alcohol in spirits by carefully heating $10 \mathrm{cc}$. of the liquid to boiling in a $50 \mathrm{cc}$. flask provided with i doubly bent tube for condenser. I cc. is distilled off in 4 to 5 minutes, $4 \mathrm{cc}$. of 2 per cent. sulphuric acid added and then gradually I gram of 
pulverized potassitum permanganate with cooling and slaking: The mostly reddish liquid is filtered and heated for 20 to 30 seconds at weak boiling, cooled and I cc. of the colorless liquid mixed with $5 \mathrm{cc}$. of con centrated sulphuric acid, then with $2.5 \mathrm{cc}$. of a fresh solution of mor phine hydrochloride (0.2 gram in $10 \mathrm{cc}$. of concentrated sulphuric acid). With 0.5 per ent. methyl alcohol the liquid becomes in 20 minutes in tense violet or violet-red in color. Voiscnet (Bull. soc. chim. [3] 35, 748) applied his recently discovered reaction of formaldehyde with niirite containing egg albumen (Ibid. [3] 33, I I98) to the detection of methyl alcohol. An amount of the alcohol corresponding to I cc. absolute is diluted to $50 \mathrm{cc}$. with water, 5 grams of potassinm bichromate and 30 ce. of 20 per cent. (by weight) sulphuric acid are added, shaken, let stand for an hour at the ordinary temperature, then distilled so as to obtain so cc. in I hour. Whese $30 \mathrm{cc}$. contain atl the acetaldehyde and are thrown away. The following $20 \mathrm{cc}$. must contain the methyl alcohol and are tested for it. Aldehydes with phenol character give a similar violct color which is, however, quite stable toward reducing agents; the formalkehyde color is not. (Gaseard ( $J$. pham. chim. [6] 24, 97) determined the molecular weight of alcohols and phenols by heating th dried sub. stance in a long-necked flask with 2 to 3 times the theore wal amount of benzoic acid anhydricle for $2+$ hours in a water or oil bath, the flask being covered. In most eases boiling ealcinm chloride solution (cold saturated) will clo for the batls. ro to $20 \mathrm{cc}$. of ether are rtin into the flask, then $5 \mathrm{cc}$. of water and 2 drops of phenolphthalein and the liquid titrated with normal potush. Molecular weight $P=p+1000 /(N-1)$, where $p=$ weight of stbstance, $N=$ number of $c c$. of canstic potash $11=$ number of cc. of caustic potash found in the blank determination with everything but the alcohol or phenol. In the case of a polyal. cohol the result is to be multiplied by the number of alcohol groups present. Where the benzoic acid ester is difficultly soluble in ether, benzene or chloroform are used. $\mathrm{ROH}+\left(\mathrm{C}_{6} \mathrm{H}_{5}, \mathrm{CO}_{2}\right)_{2} \mathrm{O}=\overline{\mathrm{C}}_{6} \mathrm{H}_{3} . \mathrm{COOR}+\mathrm{C}_{6} \mathrm{H}_{5} . \mathrm{COOH}$ 'The free benzoic acid is titrated. Klason and Carlson $(B \times r, 39,7,38)$ determined organic hydrosulphides and thioacids by titration with indine and with alkalies. $2 \mathrm{RSH}-\mathrm{I}_{2} \ldots \mathrm{R}_{2} \mathrm{~S}_{2}+2 \mathrm{HI}$. Only thiocyanic acid is itldifferent to iodine. Aromatic hydrosulphides are strong enough acids to give netutral salts with alkalies in alcoholic solution and as a restult they can be titrated with alkali and phenolphthalein in alcolol solution. With the aliphatic hydrosulphides the indication is not sharp and with thioglycolic acid it fails, even in alcoholic solution. Rosenthaler (Arch. Pharm., 244, 373) usert Nessler's reagent as a test for hydroxyl groups and found that, except benzhydrol, octyl and cetyl alcohols, all compounds that he tried containing primary and secondary alcoholic hydroxyl groups. on boiling for a minute gave reduction. these three did on boiling for some honrs with a return conclenser. Compounds with tertiary alcoholic hydroxyl do not reduce Nessler's reagent. Of compounds with phenol character--phenol, salicylic acid, guaiacol, thymol, resorcinol, phloroglucinol, and orcinol give no reduction. $x y-$ lenols and creosol an unimportant, hydroquinone, pyrocatechol and sallic acid an energetic reduction. The Sacchse liquid reduces, but not the Knupp solntion. Nessler's reagent mas be used to test amylene hydrate for fermonting anyl alcohols and citric acid for tartaric. 
Carobbio (Boll. chim. farm., 45, 365) tested for resorcinol by letting I to $2 \mathrm{cc}$. of the suspected ether flow down the wall of the test tube onto I cc. of zinc chloride with enough ammonia to give a clear solution. With 0.0 I to 0.00 I gram of resorcinol the place of contact turns yellow, then green and after a few minutes blue. Traces require considerably longer. Alcoholic hydrochloric acid added carefully forms a weakly red layer between the ring and the ether, spreading through the latter on shaking. By this reaction, o.or part of resorcinol per 1000 can be recognized in a few minutes. Hydroquinone gives the yellow ring. changing soon to a brown-red. Pyrocatechol and adrenaline give a garnetred ring. Des " lière ( $J$. pharm. chim. [6] 23, 244, 281, 332) determined glyco finding the amount of glucose pre-existing in the organ in qur nd that formed by hydrolysis. Two portions of the organ are is digested $w$ me of 10 , the other of 40 grams. The Io gram portions .15 gram of pepsin in the presence of water and a little sulphuric acid $\ldots r$ rours at $48^{\circ}$ to $50^{\circ}$. A little more sulphuric acid is added and the whole heated to I I $5^{\circ}-120^{\circ}$ in an autoclave for $I .5$ hours. The cooled contents of the autoclave are heated with slight excess of mercuric nitrate, then dilute caustic soda added to neutral or weakly alkalint reaction, the whole diluted and filtered. roo cc. of the filtrate are sha. en with 4 or 5 grams of zinc dust to separate the mercury, filtered, cc. of this treated with caustic soda till the zinc precipitated dissolve gain, water added to $55 \mathrm{cc}$. and the glucose determined gravimetricalsy or by titration. In the calculation the volume of the precipitate obtained in the purification should be subtracted from the volume of the liquid, here $200 \mathrm{cc}$. The glucose pre-existing in the solution is determined in the 40 gram portion by extracting with water, the united extracts are purified with mercuric nitrate and caustic soda, the volume brought to Iooo cc., the filtrate treated with zinc dust and the determination carried out as above. Ottolenghi (Atti. accad. Lincei, [5] I5 I, 44) stated that the reaction of Neuberg and Rauchwerger for the detection of cholesterol (with rhamnose and concentrated sulphuric acid) is not characteristic of cholesterol but is given by phytosterol from many sources. Neuberg ( $Z$. physiol. Chem., 47, 335) admitted this to be true. Windaus (Chem.-Ztg., 30, IorI) detected small amounts of cholesterol in the presence of phytosterol by the difficult solubility of cholesterol dibromide in a mixture of ether and acetic acid. Ioo cc. of a 50 per cent. mixture dissolves only 0.6 gram, $40 \mathrm{cc}$. ether and $60 \mathrm{cc}$. acid only 0.25 gram of cholesterol dibromide. Addition of a little water lowers the solubility while much water causes the phytosterol dibromide to separate out in an oily form and to crystallize with more difficulty. Cholesterol dibromide may be obtained almost quantitatively by dissolving cholesterol in a little ether and adding a solution of bromine in acetic acid ( 5 grams in Ioo cc.). The use of petroleum ether gives a cholesterol salt of different melting point.

Aldehydes, Ketones.-Meth (Chem.-Ztg., 30, 666) stated that one of Rimini's (Ann. farmacol., 98, 97) tests for formaldehycle, that of the red color with ferric chloride, phenylhydrazine hydrochloride and hydrochloric or sulphuric acid, occurs also with acrolein even though with different shade and less delicacy. Rimini's other test with phenylhydrazine hydrochloride, sodium nitroprusside and sodium hydroxide giv- 
ing with formaldelyde a bhe color gives nothing with acrolein. Schoor (Pham. Weekblud, 43, i 55) eriticized Blank and Finkenbeiner's (Fir. 39, 1326; see nuder alcohols) method for the determination of format dehyde. He added to 3 grams of the formaldehyde solution a mixture of $50 \mathrm{ce}$ of normal alkali and $50 \mathrm{cc}$. of nevtral 3 per cent. hydrogen per oxide, warming on a water bati, cooling and adding phenolphthale liti. Hence it must take 16 to 17 ec. of normal acid to ncutralize. Hérissey (f. pham chm. [6] 23, 60) determined sniall amounts of benzalcie hede by distilling so ce. From the liquid restiting from the splitting of tice glucoside, treating this with $50 \mathrm{cc}$ of a solution of a ce. of freshly rectified phenylhydrazine and $0.5 \mathrm{gram}$ of acetie acid $\mathrm{i}$. heating for 20 to 30 minutes on a water bath, then aft ing, collecting in a Gooch cricible, washing, drving : phenyllyclazone. This weight mintiplied by 0.54081 of benzatlehyde. Wallis (Pham. $/ .[+] 22,162$ ) de: sce. of water, mirs' stand. giring the (s) weigl!t livelrate by dissolving in to ece of alcohnl, digesting for 3 uns on $a$ water bath with ro $\mathrm{cc}$. of at volunetric solinm hydroxide solution, neutraliz. ing with sulphtric acicl and titrating with standard silver nitrate solution. $\left.\mathrm{CCl}_{3} . \mathrm{CH}(\mathrm{OH})_{2} \cdots, \mathrm{NaO}\right) \cdots 3 \mathrm{NaCl}+2 \mathrm{HCOONa}+3 \mathrm{H}_{2} \mathrm{O}$.

Auld ( $/$. Chem. Ind, 25, 100) detemined acetone by adding to a hot 10) per cent. catustic potash solution of the weighed liquid dropwi e a solution of 200 grams of bronnine and 250 grams of potassium . in 1 liter of water, heating for $1 / 2$ hour at $70^{\circ}$, and distilling off a womoform. The distillate is then leated with $50 \mathrm{cc}$. of alcohol and enough caustic potash to mike a u per cent. solution, using a return condenser till all bromolorm is decomposed. $3 \mathrm{CHIBr}_{3}-3 \mathrm{KOH}-\mathrm{C}_{2} \mathrm{H}, \mathrm{OH}=$ ${ }_{3} \mathrm{CO}+\mathrm{C}_{2} \mathrm{II}_{4}+9 \mathrm{KBr}+-\mathrm{H}_{2}(\mathrm{O})$. The distillate is titrated with sifere nitrate solution. 'lo 58 parts of acetone. 240 parts of bromine correspond. Jolles $(B+2,39,5,306)$ detcrmined acetone by the addition of a 3- to 4 -fold excess of tittaled primary sodium sulphite titrating back after 30 hours stinding with iodine solntion. $\mathrm{CH}_{3} \cdot \mathrm{CO} \mathrm{CH}_{3}-\mathrm{NaHSO}$ $\left.\mathrm{CH}_{3} \mathrm{C}(\mathrm{OH})(\mathrm{SO})_{3} \mathrm{Nil}\right) . \mathrm{CH}$.

Acids. Carletti (Boll. chim. fom., 45, +49) observed that furfural gires colors with the aromatic amines, at any rate with aniline, only in the presence of organic acils, not with aniline salts of mineral acids nor after the addition of a mineral acid to aniline originally combined with at1 organic acich. Two solutions are prepared; $(a)$ s grams of pure aniline are treated with $25 \mathrm{co}$ of concentrated acetic acid and diluted to $I 00$ cc. with water, and (b) I gram of freshly prepared furfural is made up to Ios ece with 0.5 pere cent. alcohol. $50 \mathrm{ce}$ of wine or vinegar are decolorized with animal charcoul, $25 \mathrm{ec}$, of 95 per ent. alcohol added, we ce. of this solution shaken with 5 drops of $(a)$. thet 5 of $(b)$. With no mineral acid there is a clistinct reddish color reaching a maximum after 30 mintules. But with $\mathrm{t}$ loge of fres hydrochloric, nitric or sulphuric acid the solution kecps its original weak green color. The reaction fails only with wines to which gypsum has been adcled. Cinarneri chtar. per. amm. Ifal. 38, go6) detected benzoic and salicrlic acids in to mato preseres by diluting and acidifying the extract with sulphuric acial $(1: 3)$, cxtacting with, 2 volume of a mixture of equal parts of cther and petroleum ether, repeating with ether, evaporating after the addition of a little weakly ammoniacal water, filtering, adding 2 to 3 
grams of freshly ignited carbon, when the odor of benzoic acid is evident. The cooled test treated with a drop of I per cent. ferric chloride gives a reddish brown precipitate in the presence of benzoic acid. A violet color changing to blood-red on shaking shows salicylic and a brown color, green on shaking, tannic acid. In the latter case the tannic acid is precipitated as iron tannate and salicylic acid detected in the filtrate by the violet color. The iron tannate is dissolved in hydrochloric acid, diluted and shaken with ether. On slow evaporation of the ether, crystals of benzoic acid appear and may be identified by the aniline blue reaction. Herzog (Festschrift Adolf Lieben, 440;Ann. 35I, 263) gave a test for lactic acid, treating the silver salt with iodine. 2 R.CHOH.COOAg $+\mathrm{I}_{2}=$ R.CHOH.COOH $+\mathrm{RCHO}+\mathrm{CO}_{2}+2 \mathrm{AgI}$. The acetaldehyde may be detected with sodium nitroprusside and piperidine. Amino acids were carefully converted in the cold into the $\alpha$-oxyacids by means of silver nitrite and their silver salts treated as above with iodine. Glycocoll, alanine and other higher homologties can thus be detected. Schloss (Beitr. chem. Physiol. u. Pathol., 8, 445) detected glyoxylic acid by means of indole and skatole. With no ring formed at contact zone between solution and skatole ( $0.2 \mathrm{gram}$ in $100 \mathrm{cc}$.) there is no glyoxylic acid present. If a red or brown ring is formed, the following test should be tried. 20 cc. of liquid are decolorized with animal charcoal, I or $2 \mathrm{cc}$. of dilute sulphuric acid added to a portion of the colorless filtrate and let stand for $\mathrm{I} o$ minutes in a water bath at $50^{\circ}$. The skatole reaction should be set up in another portion, adding about $\mathrm{I}$ cc. of skatole solution and pouring concentrated sulphuric acid down to the bottom. The first portion is tested with indole. A sharp red ring after at most 2 or 3 minutes points to the presence of glyoxylic acid. The skatole reaction alone is not positive. Glyoxylic acid to 0.000 ,or gram can be thus detected in wine. Sullivan and Crampton (Am. Chem. J., 36, 419) detected tartaric acid or tartrates by means of the crystalline structure of the calcium salt. $50 \mathrm{cc}$. of the, concentrated salt solution containing not more than 30 per cent. of dry substance are rendered alkaline with caustic potash, a few drops of 20 per cent. potassium acetate added, acetic acid to acidification and then ro cc. of 30 to 40 per cent. calcium chloritle solution. The mixture is stirred for $\mathrm{I}$ to 2 minutes and allowed to stand for $\mathrm{I}_{2}$ to $\mathrm{I} 5$ hours at room temperature. The calcium tartrate crystallizes in rhombic prisms or pyramids recognizable under the microscope. No other organic acid gives a calcium salt of similar form. Citric and oxalic acid precipitate, malic doss not, but in the presence of these acids the calcium tartrate is thro a out in needles and plates. Tocher (Pharm. I. [4] 23, 87) used a couple of reactions for the detection of citric, tartaric and malic acids. Tartaric on heating with concentrated sulphuric acid gives a black mass, citric a yellow solution and malic a dark solution. Tartaric gives with cobalt nitrate a red solution becoming colorless with excess of caustic soda, deep blue on boiling, the color fading out on cooling. Citric gives a deep blue solution, and a precipitate if the neutral solution be boiled with calcium chloride solution. Malic gives also a blue solution but no precipitate with calcium chloride and gives on heating with dilute sulphuric acid and potassium bichromate the odor of ripe fruit. Ulpiani and Parrozzani (Atti accad. Lincei, [5] I5 II, 5I7) gave a rapid determination of citric acid in lemon juices, determining 
first the approximate total acidity of the juice with normal sodium hydroxide, then putting $50 \mathrm{cc}$. in a $200 \mathrm{cc}$. flask with enough normal so. dium hydroxide to neutralize about $1 /$ ro of the total acidity. This value represents the maxinum proportion of tartaric and oxalic acids which are then precipitated after the addition of about 17 grams of calcium chloride and 5 grams of animal charcoal and boiling. The mixture is cooled, made up to volume and liltered. The following determinations are made in the filtrate: (1) 50 ec. are titrated with normal sodium hydroxide till a faint permanent turbidity appears, and (2) another $50 \mathrm{cc}$. are boiled and titrated with the caustic soda to turbidity. The difference in sodium hydroxide between (I) and (2) represents $2 / 3$ of the free and combined citric acid in the ittice. Kastle (Public Health and Marine Hospital Serico L. S. II yicnic Lab. Bull., No. 26, 3I) stated that small amounts of saccolarin heated with small amounts of a $\mathrm{re}$ agent $(5 \mathrm{cc}$. of phenol and $3 \mathrm{cc}$. of concentrated sulphuric acid) for 5 min. utes at $I 60^{\circ}$ to $\mathrm{I}_{7} 0^{\circ}$. the mass dissolved in in little water and made alkaline with twice normal caustic soda, gives a purple or deep red color according to the amount of succhatin. the limit is $0.025 \mathrm{mg}$. Salicylic and benzoic acids do not interfere, neither do cumarin or ethyl $p$-sulphobenzoate. Vanillin becomes yellow, then red in the cold; heater to $160^{\circ}$ to $170^{\circ}$ it is first blood-rerl, then almost black; after the addi tion of caustic soda it is deep clark red. With other plenols substituted for ordinary phonol in the test the following colors are obtained:

\begin{tabular}{|c|c|c|}
\hline Phenol & Saccharin at $160^{\circ}$ to $1-0^{\circ}$ & Vanillin at $100^{\circ}$ \\
\hline Pyrocatechol & Green & Dark blue to green \\
\hline Hydroquinone & $\begin{array}{l}\text { Dark red-brown with blue fluo- } \\
\text { rescence }\end{array}$ & Dark red-brown \\
\hline Resorcinol & $\begin{array}{l}\text { Salmon color with strong green- } \\
\text { yellow fluorescence }\end{array}$ & Red with weak green fluorescence \\
\hline Tricresol & Purple-red & Deep purple-red \\
\hline Phloroglucinol & Wine-red & Yellow \\
\hline Thymol & Clear blue & Clear red \\
\hline
\end{tabular}

Cumarin at $100^{\circ}$ gives colorless (with tricresol) to orange-yellow (with phloroglucinol) compounds. Stanek (Z. physiol. Chem., 47, 83, 334 : $Z$. Zuckerind. Böhmen, 3I, 316) found that choline precipitates from acic! or alkaline solutions with potassium triiodicle while betaine precipitates only from acid. To $25 \mathrm{cc}$. of at most a 5 per cent. solution of the mixture of both hydrochlorides 5 per cent. primary potassium or sodium carbonate is added and precipitation made with the triiodide; the choline periodide is filtered, washed and the nitrogen determined. The filtrate is concentrated to about $25 \mathrm{cc}$, then about Io per cent. sulphuric acid added, the liquid satur:tted with sodium chloride, and potassium triiodide added as long as a precipitate forms. This is filtered, washed with saturated sodium chloride solution and the nitrogen determined. The action of other nitrogen bases with potassitum triodide is tabulated and the method applied to the determination of choline and betaine in vegetable substances.

Derivatives of Carbonic and Uric Acids, Heterocyclic Compounds.Ackermann (Z. physiol. Chem., 47, 366) recommended benzene sulpho- 
guanidine as a means of detecting guanidine in the presence of arginine. 3 grams of guanidine carbonate warmed in $30 \mathrm{cc}$. of water are shaken with $6 \mathrm{cc}$. of 33 per cent. caustic soda and $4 \mathrm{cc}$. of benzene sulpho-chloride when, on cooling, white crystals of benzene sulphoguanidine separate out. They may be recrystallized from boiling water and boiling alcohol, and melt at $22_{2}^{\circ}$. In $100 \mathrm{cc}$. of water 0.02 gram is soluble. Arginine does not give the corresponding compound. Cumming and Masson (Chem. News, 93, 5, I7. From Proc. Soc. Chem. Ind. Vierona, 1903, July-August) gave a new method for the determination of cyanates in the presence of carbonates. $\mathrm{KCNO}+{ }_{2} \mathrm{HCl}+\mathrm{H}_{2} \mathrm{O}=\mathrm{KCl}+\mathrm{NH}_{4} \mathrm{Cl}+$ $\mathrm{CO}_{2}$. The titration is first made in the cold for carbonates, with congo red or methyl orange as indicator, then an excess of acid is added, the solution boiled and the acid excess titrated back. A second determination of the cyanic acid may be made by boiling the solution containing the above reaction products with excess of caustic potash and determining by titration the amount of the latter required to break up the ammonium chloride. Herter and Foster ( $J$. Biol. Chem., I, $257 ; 2,267)$ gave an indole determination, treating a dilute solution (I: I00,000 of water) made weakly alkaline with caustic potash with a drop of 2 per cent. $\beta$-naphthoquinone sodium monosulphonate, yielding a blue or blue-green color. With more indole, well formed crystals of a bluish color are obtained. The green color fails at a dilution of $\mathrm{I}: \mathrm{I}, \mathrm{O2} 4,000$. The compound is soluble in chloroform with red color and this solution may be used for colorimetric work. Skatole is separated from indole by distillation and determined by a colorimetric method which rests on the blue color caused by Ehrlich's reagent. Konto (Z. physiol. Chem., 47 , I 85) detected indole in putrid albumen by distilling off $I / 3$ of an alcoholic solution, making the distillate alkaline with caustic soda and distilling, making this distillate acid with sulphuric and distilling. To I cc. of this are added 3 drops of 4 per cent. formaldehyde and an equal volume of concentrated sulphuric acid allowed to flow onto it. With a trace of indole the whole solution becomes a magnificent violet-red. The reaction is visible with I part of indole in 700,000 of water, but not in 800,000 . Ronchèse ( $J$. pharm. chim. [6] 23, 336) determined uric acid with titrated iodine, IOO $\mathrm{cc}$. of urine being treated with $\mathrm{I} 5 \mathrm{cc}$. of ammonia and 15 grams of ammonium chloride, the precipitate filtered and washed with a solution of I $50 \mathrm{cc}$. of ammonia and I 50 grams of ammonium chloride per liter, brought into solution in $300 \mathrm{cc}$. of water with some acetic acid, $20 \mathrm{cc}$. of saturated borax and primary potassium carbonate solution are added and the solution titrated. The number of grams of uric acid in I liter of urine is equal to the number of cc. of tenthnormal iodine multiplied by 0.084 plus o.or. I molectle of uric acid requires 2 atoms of iodine. Sperling (Z. Oesterr. Apoth. Ver., 44, 5I) treated 2 to $3 \mathrm{cc}$. of a $\mathrm{I}$ : Ioo aqueous solution of phenyldimethylpyrazolone with 2 drops of fuming nitric acid and after the appearance of the green color, added carefully $5 \mathrm{cc}$. of concentrated sulphuric acid. A cherry-red ring was obtained at the contact zone, which spread through the whole liquid on shaking. The reaction is characteristic for antipyrine and its derivatives except amidopyrine. Other substances treated as above gave the following results: 


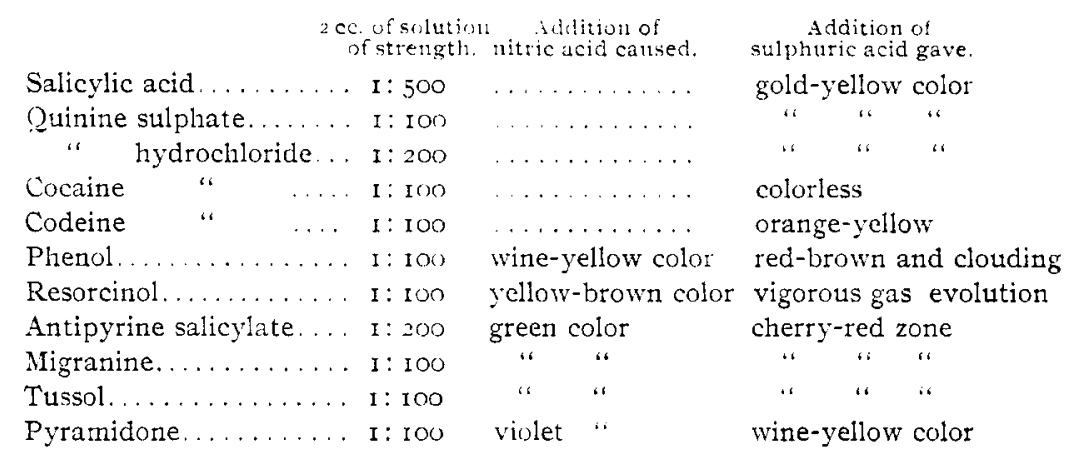

Weehuizen (Pharm. Weekblad, 43, 1105) gave a number of nicroscopic reactions for pyramidone in I: Ioo solution, with iodine-potassium iodide, bromine-potassium bromide, potassium cadmium iodide, mercuric chloride and sodium palladous chloride and in strength $1: 400$ with Mayer's solution. The precipitates are all crystalline and are characteristic. Albumens.-Arny and Pratt (Am.J. Pham., 78, I2I) determined casein in milk by adding to $10 \mathrm{cc}, 20 \mathrm{cc}$. of tenth-normal iron alum solution (48. I grams per liter) in the cold, filtering, washing, acidifying with hydrochloric acid, adding potassium iodide and titrating the filtrate with tenth-11ormal sodiun thiosulphate. Bordas and Touplain (Compt. rend., I42, I 345) made use of the insolubility of the chief albumens like egg, fibrin and casein and of gelatinous substances like diastases and peptones in pure or suitably diluted aqueous acetone for their determination. The mass must be neutral or at most only slightly alkaline or acid. 10 granns of butter, for instance, were treated with pure acetone, the residue washed with aqueous acetone, the residue contain. ing the casein and ash. I, evene and Rouiller (J.Biol. Chem., 2, 48I) determined tryptophane in the products of hydrolysis of egg albumen. The liquid to be tested is made to contain 5 per cent. sulphuric acid and treated gradually with Hopkins and Cole's reagent (Io parts of mercuric sulphate and 90 of 5 per cent. sulphuric acid). Bromine water is added till the red color of the liquicl over the precipitate begins to disappear. The liquid is filtered after 24 hours and the mercury precipitated with hydrogen sulphide. The filtrate is heated, made up to a definite vol ume, I $5 \mathrm{cc}$. of this are treated with $2 \mathrm{cc}$. of amyl alcohol and then bromine solution added with vigorous shaking till the purple color of the alcohol solution disappears. In the presence of tyrosine the mercury precipitate with the reagent is treated with 5 per cent. sulphuric acid till the tyrosine reaction disappears. In the presence of cystine ( $\mathrm{r}$ ) the cystine-tryptophane solution is titrated with bromine, (2) an acid determination is made in an aliquot portion of the solution, (3) the amount of bromine corresponding to cystine is calculated and subtracted from the value in (I). The bromine solution is stanclardized against tryptophane and eystine solutions.

Carbohydrates.-Bang (Biochem. Z., 2, 27I) determined sugar after its reduction of a copper solution by titration of the copper oxide remaining with nydroxylamine solution. The copper solution was made by dissolving 250 grams of potassium carbonate, 200 of potassium thiocyanate and 50 of primary potassium carbonate in about $600 \mathrm{cc}$. of water 
at $50^{\circ}$ to $60^{\circ}$, cooling to $30^{\circ}$ and allowing $\mathrm{I} 2.5$ grams of purified copper sulphate pentahydrate dissolved in about $75 \mathrm{cc}$. of water to flow in, filtering after 24 hours and diluting to I liter. The hydroxylamine solution contained 6.55 grams of the sulphate and 200 grams of potassium thiocyanate dissolved and made up to 2 liters with water. Io cc. of the sugar solution were boiled quietly for 3 minutes with $50 \mathrm{cc}$. of the copper solution, cooled quickly and titrated to colorless. The limit of the method lies at about $0.1 \mathrm{mg}$. of sugar. The copper reduced by the sugar precipitates as cuprous thiocyanate and the rest of the copper does also after reduction by the hydroxylamine. Browne (THIs JourNAL, 28, 439) analyzed sugar mixtures by determining the total content of reducing sugar as glucose and the polarization. If $x=$ per cent. of sugar A, $y$ of $\mathrm{B}$ and $a$ the relation of reduction capacity of sugar A to that of glucose, $b$ that of sugar $B$ to that of glucose and $R$ the per cent. of reducing sugar as glucose $a x+b y=R$ and $\alpha x+\beta y=P, \alpha$ and $\beta$ being the polarization factors of $\mathrm{A}$ and $\mathrm{B}$ respectively and $P$ the polarimeter value. $x=\frac{b P-\beta R}{\alpha b-a \beta}$ and $y=\frac{R-a x}{b}$. With these formulas the author has determined amounts of common reducing sugars like glucose, fructose, galactose, xylose and arabinose. The reduction constants of these sugars toward glucose were determined experimentally to be for fructose 0.915 , galactose 0.898 , xylose 0.983 and arabinose 1.032 . Chavassier and Morel (Compt. rend., I43, 966) stated that io cc. of a reagent ( $\mathrm{I}$ gram of $m$-dinitrobenzene dissolved in IOo cc. of alcohol and 35 cc. of 33 per cent. caustic soda added) with $20 \mathrm{cc}$. of I per cent. aqueous sugar solution gives with maltose, lactose, galactose, glucose or arabinose inside of 15 minutes, with levulose inside 2 to 3 minutes, a violet color, while solutions of saccharose and glycogen are not changed. Aldehydes and ketones without the alcohol group give a red color which can cover the violet. Uric acid gives the same color as reducing sugars. Glassmann (Ber., 39, 503) gave two indirect volumetric methods for the determination of grape sugar. In one the sugar solution is added to a boiling excess of the Liebig-Knapp solution (alkaline mercuric cyanide) or to Sachsse's solution (alkaline potassium mercuric iodide). The precipitated mercury is filtered off and dissolved in concentrated nitric acid. This solution is diluted, treated with I to $2 \mathrm{cc}$. of saturated iron alum solution and the amount of 30 per cent. nitric acid necessary for complete decolorization, then the solution is titrated with hundredthnormal ammonium thiocyanate. (a) $\mathrm{CH}_{2} \mathrm{OH}$. $(\mathrm{CHOH})_{4} \cdot \mathrm{COOH}+3 \mathrm{Hg}(\mathrm{CN})_{2}$ $6 \mathrm{KOH}=\mathrm{COOH} .(\mathrm{CHOH})_{4} \cdot \mathrm{COOH}+{ }_{4} \mathrm{H}_{2} \mathrm{O}+6 \mathrm{KCN}+3 \mathrm{Hg}$ (b) $\mathrm{CH}_{2} \mathrm{OH}$. (CHO $\mathrm{H})_{4} \cdot \mathrm{COOH}+{ }_{3} \mathrm{~K}_{2} \mathrm{HgI}_{4}+6 \mathrm{KOH}=\mathrm{COOH} .(\mathrm{CHOH})_{4} \cdot \mathrm{COOH}+{ }_{4} \mathrm{H}_{2} \mathrm{O}$ $+\mathrm{I} 2 \mathrm{KI}+3 \mathrm{Hg}$. One cc. of the thiocyanate solution corresponds to $0.001,001,5$ gram of mercury. In the other method the grape sugar solution is boiled Io minutes with a measured excess of alkaline mercuric cyanide, filtered from the mercury, the filtrate put into a Hempel nitrometer and the nitrogen evolved on the addition of hydrazine sulphate measured (Ebler, $Z$. anorg. Chem., $47,377)$. The difference between the amount of mercury taken and the amount corresponding to the nitrogen gives the amount precipitated by the grape sugar. Arnold (Ber., 39, 1227) observed that these methods of Glassmann cannot be used with urines containing 
creatinine, for this substance reduces alkaline metcuric cyanide in the cold and alkaline potassium mercuric iodide on warming. Lewinsky (Berl. klin Wochschr., 43, 125) showed that such substances as peptone, Liebig's beef extract, hydrolyzed casein, gelatin and glycogen in solution concealed the presence of varying amounts of glucose and glucoseamines. For instance in a solution containing 2 per cent. peptone 0.5 per cent. sugar gave no reduction with Felnling's solution and I per cent. gelatin concealed 0.005 per cent. sugar. Grape sugar can be approximately determined in fruit according to Lyon (THIS JOURNAL, 28, 998) by obtaining the amount of soluble stibstances and the inversion polarization. The former is obtained from the density of the solution. If $a=$ per cent. of soluble substance, $b:=$ polarization, $x=$ per cent. of glucose, $y=$ per cent. of cane and invert sugar then $x-y=a$ and I.75 $x-0.34 y=b$ or $x=(0.3+a-b) / 2.09$. Both numbers in the formula change a unit in the second decinal for a change of $2^{\circ}$ in temperature. Pellet (Bull. assoc. clim. sucr. dist., 23, ro15) observed that alcoholic digestion is of no value in sugar beet investigations and that errors come even from filtering in the alcoholic extraction. Cellulose (of the paper) absorbs sugar in alcohol solution and in the alcoholic digestion the cell substance may absorb oxygen, as has been observed by loglund and Crocker respectively. An absorption of sugar by cellulose cloes not take place in aqucous solution. Schoorl and Van Kalmthont ( $B C$. 39,280 ) gave some color reactions of the nost important sugars, criticizing some of Pinoff's (Ibid., 38, 3308). 'Ien ec. of an alcohol-sulphuric acid mixture $(750: 200), 0.05$ gram of sugar and $0.2 \mathrm{cc}$ of 5 per cent. alcoholic $\alpha$-naphthol solution give a red-violet in I minute if fructose or cane sugar were used, with $d$-glucose or milk sugar after 15 minutes (instead of 30). If the sugar solution be diluted with io cc. of alcohol, the color comes in 5 minutes with the first two sugars and with last two within $1 / 2$ hour (instead of not at all). The $\beta$-naphthol reaction is give $n$ by Pinoff as characteristic for fructose but after 20 minutes fructose gives only a slightly darker yellow color than cane sugar, while after 30 minutes both glicose and milk sugar give a weak yellow color. l'inoff's reaction with resorcinol is a not specially fortunate modification of the Selivanow test. With potassium bichromate and ammonimm chloride Pinoff said only the ketoses (fructose) gave a precipitate, but within I/2 hour cane sugar gives at least a small precipitate. The formation of calcium fructosate is the only certain test for fructose. Berg's reaction for the detection of aldoses in opposition to ketoses and non reducing polyoses (oxidation of the aldose to hydroxy acid with bromine and yellow color of this with ferric chloride) is not reliable becanse other carbolnydrates color ferric chloride yellow, even though weakly. Talon (Ann. chim. anal. appl., II, 244) found that the esters of glucose are always formed in the presence of alcohol and traces of acid, that they increase in amount with the temperature and the time and that they have no reducing power. So alcohol, even methyl alcohol, is to be aroided in tests or determinations of sugars. Glycerol esterifies like a mona tomic alcohol on glucose and fructose but its action at the same dilution is less. Weehuizen (Pharm. Wockblal, 43, 1209) observed that glucose, milk and cane sugar, starch and cellulose gire with skatole a beautiful stable violet color and with indole a brown-red, if warmed at 
the same time with strong hydrochloric acid. The skatole reaction is delicate to $I: 300,000$.

Baur and Polenske (Arb. kais. Gesundheitsamt, 24, 576) separated starch and glycogen by dissolving $0.1 \mathrm{mg}$. of the mixture in $30 \mathrm{cc}$. of water and treating with i I grams of finely divided ammonium sulphate. The starch is filtered and washed with ammonium sulphite solution (I I grams per $30 \mathrm{cc}$.). Glycogen is precipitated out of the $60 \mathrm{cc}$. of filtrate on dilution with water to $500 \mathrm{cc}$. and addition of $500 \mathrm{cc}$. of alcohol. Jolles (Ber., 39, 96; Monatsh. 27, 81; Z. anal. Chem., 45, 186) applied his titration with primary potassium sulphate to the determination of pentoses, changing them first to furfural by distilling with hydrochloric acid and steam, taking then an aliquot portion of the distillate, neutralizing, treating with a measured excess of sulphite and titrating back after 2 hours with iodine. $\mathrm{C}_{4} \mathrm{H}_{3} \mathrm{O} . \mathrm{CHO}+\mathrm{HKSO}_{3}=\mathrm{C}_{4} \mathrm{H}_{3} \mathrm{O} . \mathrm{CHOH} \cdot \mathrm{SO}_{3} \mathrm{~K}$. Pflüger (Pfüger's Arch., II4, 23I) determined glycogen by warming IoO grams of the organ in question for 3 hours in a boiling water bath with roo cc. of 60 per cent. caustic potash. After cooling, the solution is diluted to $400 \mathrm{cc}$. and precipitated with 96 per cent. alcohol. The glycogen precipitate is allowed to stand, then washed with alcohol and ether, then dissolved in hot water, the aqueous solution made up to a definite volume and the glycogen determined by polarization. It may be inverted and the sugar determined.

Alkaloids.-Georges and Gascard (J.pharm. chim. [6] 23, 513) stated that the color of a neutral or weakly alkaline solution of morphine with iodic acid (yellow to reddish yellow and yellow-brown if made weakly alkaline with ammonia) may be used for the colorimetric determination of morphine. The iodic acid color is sharpest at dilutions from $I: 500$ to I: 5000 ; the iodic acid-ammonia color at dilutions greater than $I: 2500$. The first color reaches a maximum in $1 / 2$ minute and remains unchanged for I 5 minutes. The alkaline color is at a maximum after 2 to $3 \mathrm{~min}$ utes. Mai and Rath (Arch. Pharm., 244, 300) gave another colorimetric determination of morphine, using Marquis's reagent ( 2 drops of 40 per cent. formaldehyde and $3 \mathrm{cc}$. of sulphuric acid). One cc. of a $\mathrm{I}: \mathrm{io0}$ solution of morphine is evaporated in glass on a water bath and the residue stirred with I cc. of the reagent, the deep violet colored solution put in little tubes of about Io mm. width and after washing out the dish, diluted with $4 \mathrm{cc}$. of sulphuric acid. The limit of delicacy is about $0.000,03$ gram of the alkaloid. Radulescu (Bull. Soc. Sciinte Bucuresci, 14, 602) added to a clear solution containing $1: 300,000$ or more of morphine, a kernel of sodium nitrite and an acid, making the solution alkaline before the end of the gas evolution with concentrated aqueous caustic potash. The solution is pale red to deep ruby-red according to concertration. The color disappears on acidification, reappears on making alkaline and is not taken up in ether, chloroform, carbon bisulphide or benzene. On long standing or on boiling, the acid solution loses its property of becoming colored by alkalies. Herder (Arch. Pharm., 244, I20) observed that the ease of solubility of alkaloid precipitates in alkali and alkaline earth mercuric iodides decreases with rise of atomic weight of the metal and that differently from the precipitate in aqueous solutions which in 30 per cent. chloralh ydrate is almost always crystalline. The limits of sensibility of pure alkaloids toward caesium mercuric iodide in aqueous (I) 
and in 3 per cent. chloral hydrate (II) solutions and toward barium mercuric iodide in aquents (III) and in chloral hydrate (IV) solutions are given as follows:

\begin{tabular}{|c|c|c|c|c|}
\hline & $\therefore$ & it. & III. & IV. \\
\hline Berberine. & i: 300,000 & I: 65,000 & I: 500,000 & I : 80,000 \\
\hline Hydrastine and canadine. . & $1: 30,000$ & I : 2000 & I $: 38,000$ & I: 2400 \\
\hline Str & I : 200,000 & I: 40,000 & $1: 220,000$ & $I: 43,000$ \\
\hline Bru & I : 40,000 & I : 10,000 & I $: 4$ I, 000 & $x: I I, 000$ \\
\hline Qu & I: 100,000 & I : 20,000 & $1: 10,000$ & I: 25,000 \\
\hline Cinc & I $: 90,000$ & $1: 10,000$ & I $: 100,000$ & $I: 12,000$ \\
\hline 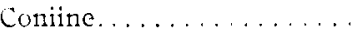 & $1: 1300$ & I : I 1000 & I: $\mathrm{I}_{300 \mathrm{~b}} \mathrm{~b}$ & 1: 1000 \\
\hline
\end{tabular}

The alkaloids were detected and localized in sections of a number oi plants. Coniine gives no precipitate in aqueous solution. The section treated with barium mercuric iodide solution is washed quickly with water and laid in a 0.5 per cent. solution of potassium bichromate in 30 per cent. chloral hydrate and acidified with a few drops of hydrochloric acid A vellow to yellow-brown solution indicates the alkaloid. Jonescu ( $B$ er. pharm. Gus, I6, 130) obscrved that by 'Thoms's method of precipitation with potassium bismuth iodide and decomposition of the precipitate with alkali not only atropine and hydroscyamine but quinine, caffeine and antipvine may be nearly quantitatively precipitated. Frons I gram of quinine used the author obtained 0.9405 gram, of caffeint 0.9546 and of antipyrine 0.9273 gram. Monti (Gar. chim. ital., 36 II, 477 ) criticized the reaction of Alvarez for aconitine and gave one of his own. The alkaloir (0.0002 to 0.001 gran) was treated in porcelain with 2 to 4 drops of stlphuric acid (d. 1.75 to r.76) lieated for 5 or 6 min utes on a boling water bath, then a snall amount of resorcinol added and the whole warned further. A yellow-red color appears, attaining a maximum after 20 minutes. Thus 0.0001 gram can be detected. Reichard (Chem.-Ztg., 30, Io) on picrotoxinc: Pharm. Zig., 51, I68, 59r on cocaine, 532 on quinoidine, $S_{1}$; on opiun alkaloids; Pharm. Centrh., 47,247 on morpline, 347 on cocaine, 473 on berberine, 623 on thebainc. 727 on codeine, 1028, 1048 on narceine) has again published a series of articles ot1 alkaloids.

Coloring Matirials, Oils.-Green, Yeoman and Jones (Mon. sici. [4] 20 I, ISI) gave a method for the systematic analysis of colors on animal fibers. The metlod includes two operations; in the first the color is removed from the fiber and its chemical behavior studied, in the second it is reduced and the course of its reoxidation studied. Given the coloring matter alone it is reduced with zinc dust and oxidized with air and with chromium trioxide; if on the fiber it is reduced with hydro. sulphite and oxidized with air and potassium persulphate. Their classification follows: I. Iecolorized by hydrosulphite and regenerated in air: azines, oxazines, thiazines, indigo. II. Decolorized by lyodro sulphite, not regenerated in air but by chromium trioxide: tripheny. methane colors. JII. Destroyed by hydrosulphite: nitroso and nitroazo colors. IV. Not changed by hydrosulphite: pyrones, acridines, quinoleins, thiazoles, certain anthracene colors. V. Changed to brown products by hydrosulphite and regenerated in air or by potassium per. sulphate: most anthraccne colors. Knowing the class, chemical ractions and shade the choice is limited to a few closely allied colors. Grafe 
(Chem.-Ztg., 30, 298, 299) gave the following main differences between lignite pitch and other pitches.

\begin{tabular}{|c|c|c|c|}
\hline Melting point. & $\begin{array}{c}\text { Residue after } \\
\text { extraction with } \\
\text { benzene. }\end{array}$ & Sulphur. & Iodine value. \\
\hline$\ldots \ldots \ldots \ldots 86^{\circ}$ & 0.0 & 2.14 & 93.7 \\
\hline$\ldots \ldots \ldots \ldots g \mathrm{~g}-92^{\circ}$ & 46.0 & 0.31 & 50.0 \\
\hline Wool fat pitch........... $32^{\circ}$ & 0.0 & 0.00 & 36.9 \\
\hline Stearin pitch............. $43^{\circ}$ & 0.0 & 0.67 & 40.4 \\
\hline Petroleum pitch $I, \ldots \ldots \ldots \ldots 33^{\circ}$ & 2.0 & 1.17 & $49 \cdot 4$ \\
\hline Petroleum pitch II......... $73^{\circ}$ & $3 \cdot 5$ & I. 09 & 70.3 \\
\hline Petroleum pitch III ........ I $26^{\circ}$ & 4.0 & 1.00 & $103 \cdot 5$ \\
\hline Lignite "goudron" ......... $52^{\circ}$ & 0.0 & 1.88 & 66.5 \\
\hline Wood pitch........... $195^{\circ}$ & 42.0 & 0.00 & 140.0 \\
\hline
\end{tabular}

A test for phenols which serves to distinguish lignite pitch from other pitches is given. A little of the asphalt is pulverized and boiled with some normal caustic soda and filtered. A little of a solution of a few drops of aniline in $\mathrm{r}$ cc. of hydrochloric acid and Io of water with some sodium nitrite solution added in the cold is added to this alkaline liquid. A red or reddish brown color or precipitate appears according to the phenol content. Without phenols the liquid is only yellow. Valenta (Ibid., 30, 266) used methyl sulphate in the detection and determination of tar oils. It dissolves the hydrocarbons of the benzene series or mixes with them in all proportions while hydrocarbons with open carbon chain and petroleum distillates do not dissolve in the cold and even esters are difficultly soluble. A measured amount of the oil sample is poured into a $100 \mathrm{cc}$. glass stoppered measuring cylinder and $\mathrm{I} .5$ to 2 times as much methyl sulphate added. The whole is shaken and the volume of the lower liquid after separation read, the difference giving the amount of oil dissolved. The tar oils may be precipitated from solution by caustic potash. A gravimetric determination is possible if the caustic soda be neutralized, the whole shaken with alcohol and the oil weighed after driving off the latter. Rebs (Protokoll I. Stzg.Komm. Bekämpf. Missverständ., Herst, etc., Farben u. Malmaterialien Nürnberg, I906, 35) determined turpentine resins or abietic acid in resins of various sorts, oil and copal lacs, pitch and paper by treating ro grams of substance with 20 to $25 \mathrm{cc}$. of 10 per cent. alcoholic potash, warming, decomposing the soap, after cooling, with dilute hydrochloric acid and filtering, washing and drying the separated resin. The pulverized resin is extracted with $50 \mathrm{cc}$. of warm petroleum ether, the abietic acid precipitated from the filtered solution as ammonium salt, separated and the ammonia driven of by gentle heat. The remaining resin-like mass gives the resin content of the substance. For less accurate work the substance may be extracted with benzene and the saponification omitted. Vaubel ( $Z$. öffentl. Chem., I2, 107) simplified his last year's method for determining turpentine oil in the commercial product by adding to $\mathrm{I}$ to 2 grams of oil in chloroform IOO $\mathrm{cc}$. of water, 5 grams of potassium bromide and Io $\mathrm{cc}$. of concentrated hydrochloric acid or a corresponding amount of sulphuric acid and then titrated potassium bromate solution till a permanent bromine color appeared. Genuine oils of turpentine have a bromine absorption of 220 to 230 while that of substitutes falls as low as 16 sometimes. Paulmyer (La Savonnerie Marseillaise, 6, No. 62; 
Seifensiederztg. 33, 286) made use of the "critical solution temperature" of various fatty oils for detecting adulterations in cocoanut oil. A cloudy mixture of fatty acids warned with acetic acid will clear up suddenly and the temperature at which it does so is constant for each acid (critical solution temperature). With pure cocoanut oil fatty acid, the liquid clears at $33^{\circ}$. Warmed a little above this and allowed to cool with stirring it will cloud at $33^{\circ}$. The value for various acids is:

\begin{tabular}{|c|c|}
\hline Cocoanut oil..... $33^{\circ}$ & Rape oil..... 107 "Palmkernöl" . $49^{\circ}$ \\
\hline Earthnut oil .... $90^{\circ}$ & . $72^{\circ}$ Stearic acid... $94^{\circ}$ (commercial) \\
\hline Sesamé oil... & Oleic acid..... $98^{\circ}$ \\
\hline Niger oil. & Cotton oil \\
\hline Castor oil & "Mafentalg". . \\
\hline
\end{tabular}

With mixtures of the fatty acids the difference in solubility temperatures is proportional to the quantities of single acids present. Twitchell (This Journal, 28, 196) found that a fat with excess of water and less than I per cent. of naphthalenestearosulphonic acid will be almost completely saponified in 8 to ro hours. This acid tried on a soluble glyceride, triacetin, showed about the same hydrolyzing power as hydrochloric acid, but the latter has practically no action on an insoluble glyceride like a common fat while the organic acid works almost as well as on a soluble ester. The capacity of these sulpho fatty acids to dissolve as well in fatty acids as in water and to make fatty acids soluble is of value in the separation of solid and liquid fatty acids.

Butter, Milk.-Robin (Compt. rend., 143, 512) detected cocoa fat and margarine in butter by means of the facts that the fatty acids of cocoa fat are nearly completely soluble in 56.5 per cent. alcohol at $15^{\circ}$ while those of butter are only partly and those of margarine difficultly soluble; and that the content of water-soluble fat in butter is much larger than in the others. The butter sample is heated with alcoholic caustic potash and the liquid so diluted with water after cooling that a 56.5 per cent. alcohol results. A blank determination with the same amount of alcoholic caustic potash is carried out, and both are titrated with half-normal hydrochloric acid in 56.5 per cent. alcohol. The difference gives the amount of acid needed for the separation of the fatty acids in the first flask and the soap there is decomposed with this amount of acid, the liquid dilited to $150 \mathrm{cc}$. with 56.5 per cent. alcohol, cooled to $15^{\circ}$ and filtered. In $50 \mathrm{cc}$. of the filtrate is found by titration with tenthnormal caustic potash the amout of fatty acids soluble in 56.5 per cent. alcohol. Another $50 \mathrm{cc}$. are evaporated to $15 \mathrm{cc}$, the water-insoluble fatty acids filtered out, dissolved in a mixture of alcohol and ether, titrated, thus giving the amount of fatty acids soluble in 56.5 per cent. alcohol but insoluble in water. The difference between these two values gires water-soluble acids.

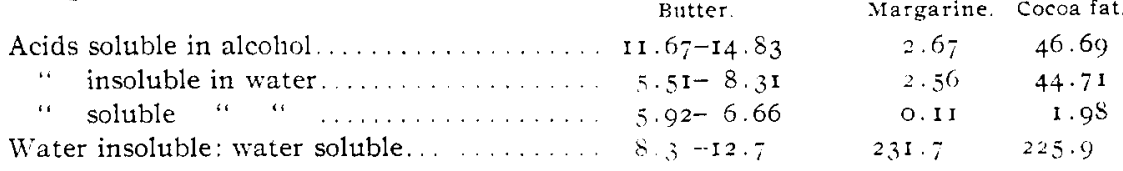

Alcock (Pharm. J. [4] 23, 28) detected formaldehyde in milk by adding to $2 \mathrm{cc}$. the sane volume of 20 per cent. caustic potash, shaking hard, hen adding an excess of strong hydrochloric acid and warming carefully. 
A coagulum is obtained, colored more or less deep violet according to the amount of formaldehyde, while the liquid below remains colorless. Bonnema (Pharm. Weekblad, 43, 434) found that the mean freezing point of milk is $-0.555^{\circ}$ and that it is influencd by dissolved crystallizable substances. The amount of water added can be determined by means of the change in freezing point. $\mathrm{D}=\frac{0.555 \times 88.5}{\mathrm{w}+88.5}$ or $\mathrm{w}=\frac{0.555 \times 88.5}{\mathrm{D}}-88.5$, where $\mathrm{w}$ is the weight of water added in grams and $\mathrm{D}$ is the freezing point in degrees below zero. This formula applies to milk with an average of 88.5 per cent. water. The freezing point rises a few hours after milking because of the formation of ammonia by bacteria and by which some phosphates are precipitated. The subsequent lowering is due to the formation of lactic acid which dissolves some of the precipitated phosphates. Comanducci (Rend. accad. scienze fisiche e matem. Napoli, 1906, April) observed that a certain amount of pure milk requires always the same amount of potassium permanganate to oxidize the organic matter in it. Watering can be detected in this way. I cc. of cow's milk requires 50 to $52 \mathrm{cc}$. of tenth-normal permanganate, goat's milk 44 to 46 , sheep's 43 to 48 , ass's 55 to 58 , woman's 53 to 60 , these oxidation indices sinking if the milk is adulterated. Cow's milk with ro per cent. of water requires $44 \mathrm{cc}$. permanganate for I cc., 20 per cent. 39. With half the cream removed the oxidation index fell also to 44 to 46. Cow's milk with an oxidation index of less than 50 is therefore suspicious. Lelli (Arch. farmacol., 5, 645) detected primary sodium carbonate in milk by means of aspirin. Milk, an equal volume of water and a little aspirin are heated to $60^{\circ}$, the opaque solution filtered, and the filtrate treated with a little ro per cent. ferric chloride solution. In presence of the carbonate an abundant red-yellow precipitate is formed. 0.5 per cent. of carbonate can be detected. Trillat and Sauton (Compt. rend., I42, 794; I43, 6; Bull. soc. chim. [3] 35, 906, I 207) gave a determination of the albuminous substances of milk and the casein of cheese, making use of the property of formaldehyde of rendering these albuminoids insoluble without changing their weight. $5 \mathrm{cc}$. of milk are diluted with $20 \mathrm{cc}$. of water, the liquid boiled 5 minutes, 5 drops of commercial formaldehyde added, the liquid boiled for 2 or 3 minutes longer, allowed to stand for 5 minutes, treated with $5 \mathrm{cc}$. of I per cent. acetic acid, shaken and the pulverulent precipitate collected on a tared filter. The precipitate is washed with water, extracted with acetone, dried at $70^{\circ}$ to $80^{\circ}$ and weighed. The casein determination is similar.

Blood, Glucosides.-Carlson (Z. physiol. Chem., 48, 69) stated that 3 per cent. hydrogen peroxide is to be preferred to ozone in turpentine oil for the guaiac blood test, as it gives a sharper and more certain reaction. Schumm (Ibid., 50, 374) disagreed with this. Horoskiewicz and Marx (Berl. klin. Wochschr., 43, I I 56) observed that io to I5 per cent. quinine solution is a good extracting agent for old blood flecks, giving a brown yellow solution with a characteristic absorption band between $C$ and $D$ (wave lengths 628 and 596) instead of the original oxyhemoglobin bands. Eight per cent. quinine solution mixed with the blood in ratio $2: 4$, heated slowly and gradually to boiling and treated after cooling with 2 to 3 drops of fresh ammonium sulphide solution will give with normal blood a dirty brown-green, but if the blood contain carbon 
monoxide it stays carmine-red. Neisser and Sachs (Ibid., 42, 44; 43, 3) detected human blood by the use of specific sera. If human serum be mixed with an antiserum obtained by treatnont of rabbits with human serum a mixture is obtained which is en pable of interaction. If a serum hemolysin be added, it must remain inctive. Ony hmman and ape's sera ciuse cessation of hemolysis in this case, all others hate s!own themselves inactive. Blood spots 3 months olc on linen gave the reaction. Rabbit serum $(0.25 \mathrm{cc}$ ) is placed in the liquid to be tested for hitman blood and mixed witl the antiscrum (prepard from rabbits treated previously with human serumi), the mixture allowed to stand for i hour at $37^{\circ}$, then I cc. of 5 per cent. sheep blood emulsion added and let stand again at $37^{\circ}$ will give proof of the presence of human blood, if hemolysis fails to appear. It is prevented by the interference of 0.000 I cc. of human serum and even $0.000,00 \mathrm{I}$ and o.000,000I $c c$. can be detected by distinct differences in the hemolytic action. The method is at least as delicate as the detection by precipitation. I'iorkowski ( $B \mathrm{Cr}$. pharm. Ges., 16, 226) observed that the hyclrocke liquid gives coagulation with human but not with cow's milk. Every elear hliman body liquid shows this reaction. Cow's milk reacts similarly with cattle serum. The hydrocele liquir gires soon with human blood a red precipitate while other bloods dissolve; only lromologous bloods are precipitated, heterologous are dissolved. Sardla and Caffart (Compt. rond., I43, 25I) found that if a drop of blood solution be evaporated slowly on a microscope slide, then treated successively with a drop of chlorine water, one of pyridine and one of ammonium sulphate solution, many chlorhematin crystals, rhomboidal rols of varying sizes isolated or in groups of an intense brown-red or bright red color, appear. At the same time the intense red hemmochromogen crystals forn in varying numbers in star, tuft and brush shapes. Van Itallie (Pham. Wrohblad, 43, 27, 33; also Ber. pharm. Ges., I6, 65) found that the blood of men and apes contained catalyzers eren after being heated to $63^{\circ}$ for $1 / 2$ hour. $5 \mathrm{cc}$. of blood (r: IOoO) were so heated, then cooled to $15^{\circ}$ and mixed with $3 \mathrm{cc}$. of I per cent. nentral hydrogen peroxide solution when the blood of men and apes liberated oxygen while that of horses, cattle, swine, goats, sheep, rabbits, rats, hares, hens, loves, bony fishes and frogs did not. Woman's milk too, giving unheated $24.8 \mathrm{cc}$. of oxygen, when heated in the same way for 15 minutes gave i 8 cc., 45 minutes 7.5 and 60 minutes $4.0 \mathrm{cc}$. of oxygen. The conclusions to be drawn from the above were opposed by Arnold (Apoth. Ztg., 21, 220) and upheld by Van Itallie (Ibid., 2I, 230).

Bread, Flour.--Pohl ( $Z$. angew. Chen., I9, 668) determined alcohol in freshly baked bread by distilling, after addition of water to prevent burning, in portions of about $\mathrm{I} \mathrm{kg}$. The united distillates from about $4.5 \mathrm{~kg}$. were several times redistilled, each time after saturation with sodium chloride, only a part being distilled. The last time the distillate was saturated witil calciun chloride and a part distilled ofi. From the density determination in the first $50 \mathrm{cc}$. of this the alcohol was calculated. It was then salted out with potash, distilled and converted into ethyl iodide for identification. $0.07+4$ and 0.0830 gram were found in white bread prepared from leaven, 0.0 .508 and 0.0547 gram in that from compressed yeast. Marion (Ann. chm. anal. (ippl., Ir, 1.34) de- 
termined gliadin by digesting io grams of flour with $50 \mathrm{cc}$. of alcohol ( $73^{\circ}$ French) in a closed flask at $40^{\circ}$ to $45^{\circ}$, shaking frequently, cooling to $15^{\circ}$ to $20^{\circ}$, decolorizing with 0.8 gram of animal charcoal, filtering and polarizing. The percentage of gliadin is equal to the reading in minutes multiplied by 0.0722 . Shaw (THIS JoURnAL, 28, 687) tested bleached flour by boiling I kg. of it for 4 hours with 95 per cent. alcohol, evaporating the filtrate and wash alcohol nearly to dryness, and extracting the residue with a mixture of equal parts of alcohol and ether. This was evaporated to a syrupy consistency, allowed to dry in a thin film on the inside of the dish and a drop of a solution of diphenylamine in stlphuric acid caused to flow over the surface. The drop called forth a blue color in bleached flours, none in unbleached, the color being due to higher oxides of nitrogen. Gastine (Compt. rend., 142, I 207) gave a new method for the analysis of flour and the detection of rice in wheat flour. The flour was moistened with a solution of coloring matter, the mass dried carefully, heated for a few minutes at $I \mathrm{IO}^{\circ}$ to $130^{\circ}$ and then investigated under the microscope in a drop of cedar oil or Canada balsam. The hilum of the starch kernel, at least of some forms of starch, shows in the form of red points ("Punktierungen"). The polyhedral starch kernels of rice give a plain, relatively large reddish hilum, the wheat starches seldom show one. Various blue, green, brown and orange coal tar colors were used, the most suitable concentration being 0.05 gram per roo grams of 33 per cent. alcohol. One to 2 per cent. of rice flour can be detected with certainty. Maize and buckwheat starch granules behave like that of rice, and many other starch granules like those of the wheat.

Wine,-Billon (Ann. chim. anal. appl., I1, 127) observed that the total alkalinity of wine ash as ordinarily determined and the alkalinity of the ash of salts precipitated from wine by an alcoholic ether mixture always lie close together but the difference is never negative; for Ioo cc. calculated as sulphuric acid it is about 0.01 and never exceeds 0.02 gram. But if the wine contain free sulphuric acid the alkalinity of ash of salts precipitated by the mixture remains unchanged while the total alkalinity is lowered and the difference becomes negative. This is the best test for free sulphuric acid in wine. With wines containing much calcium sulphate it is necessary to add potassium chloride to take care of the tartaric acid. The same author (Rev. intern. falsific., 19, 57) gave also a method for the determination of glycerol in wines. 50 cc. of an unsugared wine are concentrated to I $5 \mathrm{cc}$., Io per cent. calcium hydroxide added in slight excess, and the mixture evaporated to sirupy thickness. The cooled residue is washed with absolute alcohol and then with absolute ether completely into a roo cc. flask and filled with the latter to the mark. All except glycerol is precipitated. An aliquot portion of the filtrate is evaporated, dried and weighed; the residue is pure glycerol. With more than ro per cent. sugar an amount of slaked lime equivalent to the sugar content is added to the $I_{5} \mathrm{cc}$. concentrate, the whole evaporated to sirupy thickness and the residue extracted 7 or 8 times with Io cc. of alcohol each time, cooled and made up to roo cc. An aliquot portion of the filtrate is evaporated, the residue extracted with alcohol and ether and the determination carried out as above. Cordier (Bull. sciences pharmacol., 13, 79) 
tested wines for poisonous substances by lowering the alcohol content to 8 per cent., adding 25 grams of sugar per liter, introducing a colony of wine yeast and letting the liquid stand in a well stoppered bottle for 8 days. The pressure developed and the gas evolution give with some practice without further test the grade of activity and the increase of the yeast. If the wine contain any poisonous substance, it cannot be worked into a sparkling wine. Primary potassium sulphate hinders the test when present in considerable amount only, but traces of fluorides and other poisonous substances are enough. Mycodoma rini and $M$. aceti appear to be still more sensitive. Ross and Irestrezat (A nn. chim. anal. appl., II, 4I) detcrmined the volatile acids of wine by distilling $20 \mathrm{ce}$. under diminished pressure, repeating the distillation iwice, aclding 20 cc. of water each time. With lactic acid present, about 5 ce. must be left in the flask each time, otherwise the wine can be distilled almost dry without danger of decomposition. The volutile acids may be ti. trated in the distillate using phenolphthakin or determined by differ ence between total acidity and non-volatile acid content. Titali ( $V$ ortrag VI. Internat. Kong. angew. Chem. Rome, 1906; Boll. chim. fam., 45, 70I) found that toluene extracts only salicylic acid from aqueous and alcoholic solutions. The evaporated tolnene extract naly be taken up with water and tested with ferric clloricle or a solution of copper sulphate so dilute that it is colorless. If the solution tested by the lat ter substance be evaporated to dryness the residue is green, which is not true without the acid. The test nuay be used on wines and foodstuffs. Schmidt (Z. Nahr.-Genussm., II, 386) distinguished between fermentation vinegar and "vinegar essence" by making the sample alkaline with caustic soda, evaporating an amyl alcohol extract, adding water and a little sulphuric acid and treating with iodine-potassium iodide solution. If the mixture is unchanged the rinegar is "essence": if a clond or precipitate appears, it is furmentation vinegar. Very small amounts of fermentation vinegar are tested as above in roo ce. of distillate from sample.

Fibers in Mixd Weaves.-Lecomte ( $J$. pharm. chim. [6] 24, 447) gave a method which makes it possible to distinguish and to count with a magnifying glass the threads of differcnt fibers in mixed weaves. It consists in diazotizing the silk and wool which contain each an amino group and to couple on a phenol group in alkaline solution. Wool contains also sulphur and so by simultancous action of an alkaline plunibite solution, lead sulphide is formed, concealing the azo color. Plant fibers contain neither of these sibstances and remain unchanged. One decimeter of decolorized weave is put in to $30 \mathrm{cc}$. of to per ecnt. nitricacid $30 \mathrm{cc}$. of 5 per cent. aqueous nitrite solution added during 3 minutes gradually and with stirring, allowed to stand ro minutes, washed for 2 minutes with water, pressed out and cut into 2 pieces. Over one is poured $40 \mathrm{cc}$. of $\beta$-naphthol plumbite solution (50 grams of caustic soda in $500 \mathrm{cc}$. of water, 25 grams of lead acetate in $300 \mathrm{cc}$. of water slowly addedand 5 grams of $\beta$-naphthol added to the elear liquid); the other piece is treated with $40 \mathrm{cc}$. of resorcinol-plumbite solution (2 grams of resorcinol in place of the naphthol). The weaves are washed after I hour at not abowe $20^{\circ}$ with ranning water for 1.5 minutes, placed for 5 minutes in row $c c$. of 0.5 per cent hydrochloric acid, washed again for an hour with runting water, 
pressed out between white filter papers and dried in the dark. Silk will be colored rose-red by the $\beta$-naphthol solution, orange-yellow by the resorcinol, the wcol black by both, while the plant fibers will remain white.

A portion of the work for this review was done in the library of the department of chemistry of Cornell University, through the courtesy of Professor L. M. Dennis, for which the writer desires to express his thanks.

UNIVERSITY OF NEBRASKa,

LINCOLN, NEB.

\section{INTER-RELATIONS OF THE ELEMENTS. ${ }^{1}$}

BY HERBERT N. MCCOY.

Received Januaty I, 1908.

The history of chemistry from the first to the sixth decade of the igth century shows all too clearly how unsuccessful were the attempts of Dalton and of his contemporaries and successors to fix the atomic weights of the elements by means of arbitrary rules regarding the numbers of atoms which unite with one another, even when these rules were supplemented by knowledge of chemical behavior. Consistent results were obtained only by the aid of the auxiliary hypothesis of Avogadro; which, proposed in I $8 \mathrm{I} \mathrm{I}$, almost unappreciated until after its reanimation by Cannizzaro in 1858 , to-day is the corner-stone of the magnificent structure of which the atomic hypothesis is the foundation. Between the physical and chemical properties of the elements and their atomic weights, fixed by means of the hypothesis of Avogadro, there are, as is well known to every chemist, the most fundamental relationships. Of these relationships none is perhaps more significant than that discovered in I8Ig by Dulong and Petit. This law supplemented by the relations discovered by Neumann and by Kopp means, simply, that for solid substances, the atoms of all elements, either free or combined, have approximately the same capacity for heat. A few months ago Lewis showed that atomic heats at constant volume are much more nearly constant than the ordinary values, which refer to constant pressure.

During the fifty years following Dulong and Petit's discovery many other relations, more or less quantitative, were found between the properties of elements and their atomic weights; all these relationships were correlated, in I869, in the Periodic Law of Lothar Meyer and Mendeléeff, which may be concisely summarized in the statement that, in general, the properties of elements are periodic functions of their atomic weights. The comprehensive nature of the law is best appreciated when we remember that these properties include chemical nature, valence, atomic volume, hardness, thermal expansion, crystalline form, conductivity for heat and electricity, melting-point, boiling-point, spectral wavelength and ionic mobility, as well as other properties of less importance. What could illustrate more forcibly the validity of this great law than the startling coincidence in properties of the element, germanium, discovered by Winkler in I 886 , and the hypothetical eka-silicon described by Mendeléeff sixteen years earlier, or the equally accurate predictions of the same famous chemist concerning eka-boron and eka-aluminium.

1 Read at the Chicago meeting of the American Chemical Society. 